Portland State University

PDXScholar

$11-5-1993$

\title{
The Effectiveness of Semantic Mapping on Reading Comprehension
}

\section{Sharon Fredricks}

Portland State University

Follow this and additional works at: https://pdxscholar.library.pdx.edu/open_access_etds

Part of the Bilingual, Multilingual, and Multicultural Education Commons Let us know how access to this document benefits you.

\section{Recommended Citation}

Fredricks, Sharon, "The Effectiveness of Semantic Mapping on Reading Comprehension" (1993). Dissertations and Theses. Paper 4667.

https://doi.org/10.15760/etd.6551

This Thesis is brought to you for free and open access. It has been accepted for inclusion in Dissertations and Theses by an authorized administrator of PDXScholar. Please contact us if we can make this document more accessible: pdxscholar@pdx.edu. 
AN ABSTRACT OF THE THESIS OF Sharon Fredricks for the Master of Arts in TESOL presented November 5, 1993.

TITLE: The Effectiveness of Semantic Mapping on Reading Comprehension APPROVED BY MEMBERS OF THE THESIS COMMITTEE:

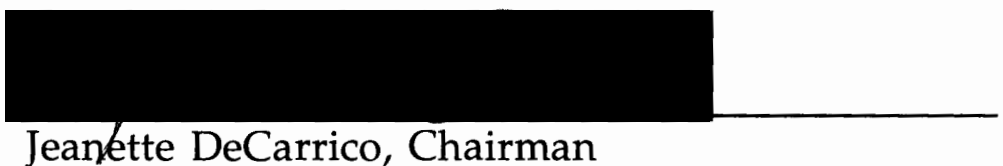
Jeanette DeCarrico, Chairman
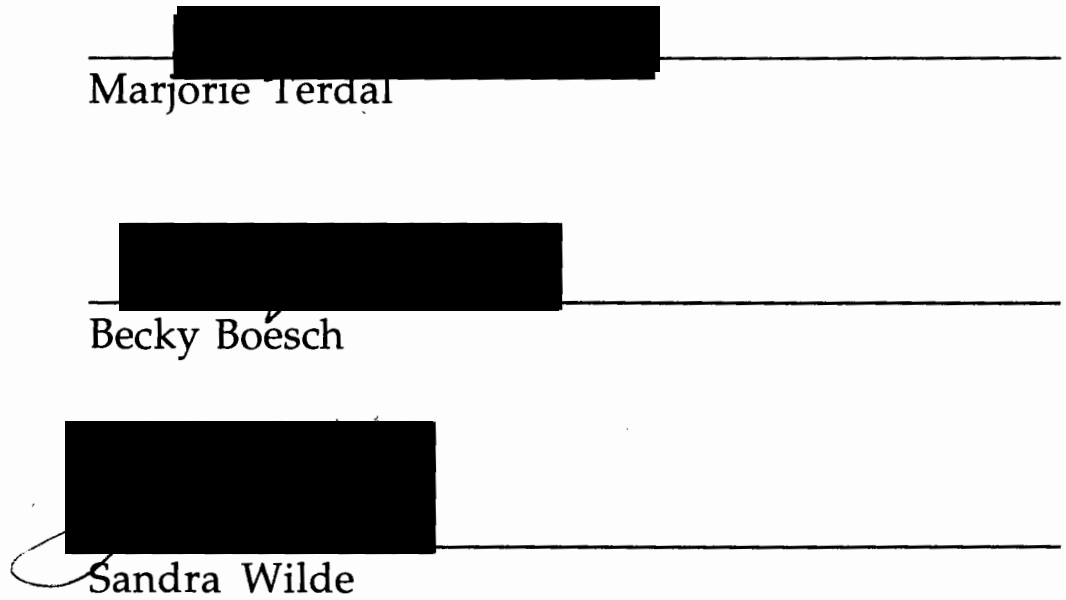

It is the goal of all reading instructors to use techniques that will enhance reading comprehension. This is certainly no less so in the second language classroom. Studies have shown that readers possess schemata for text structure that is activated during the reading process. It has also been shown that a reader's textual schemata may be culturally influenced and that second 
language students may possess textual schemata that conflicts or interferes with the structure of the text making comprehension more difficult. For this reason, second language learners may benefit from explicit instruction in text structure and content relationships. Semantic mapping is a text organization strategy which may be used to explicate text structure and content relationships with both expository prose and fiction.

The purpose of this study was to use semantic mapping to explicate the structure and content of short fiction and to measure the effect, if any, on comprehension. For the purposes of this study, comprehension was defined two ways: (1) recognition comprehension, which is the ability to retain and recall factual detail from text content, and (2) comprehension as evidenced by the use of certain critical thinking skills, i.e., elaboration and supplementation in forming written responses.

Two hypotheses were posed:

1. The use of semantic mapping will result in an increase in recognition comprehension by a treatment group of English as a second language readers using a semantic mapping strategy, as compared to a control group using an advance organizer, based on a combination multiple choice and true/false quiz.

2. The use of semantic mapping will result in greater use of elaboration and supplementation by a treatment group of English as a second language readers using a semantic mapping strategy, as compared to a control group using an advance organizer, based on an analysis of a quiz requiring written responses.

In order to determine the results of this study, $\underline{\mathrm{t}}$-tests were used to compare the mean scores between groups. In the case of recognition 
comprehension, the group receiving the treatment, semantic mapping, did score significantly higher than the control group. In the case of comprehension, as evidenced by the use of elaborations and supplementations in written responses, the group which used semantic mapping showed a higher level of use, but the difference was not statistically significant.

A Mann-Whitney $U$ test ranked the subjects' scores individually on an ordinal scale and then compared the means between groups. In the case of elaborations the treatment group showed a significantly higher level of use. However, there was no corresponding significant difference in the case of supplementations. 
THE EFFECTIVENESS OF SEMANTIC MAPPING ON READING COMPREHENSION

by

SHARON FREDRICKS

A thesis submitted in partial fulfillment of the requirements for the degree of

MASTER OF ARTS

in

TESOL

Portland State University

1993 
TO THE OFFICE OF GRADUATE STUDIES:

The members of the Committee approve the thesis of Sharon Fredricks presented November 5, 1993.
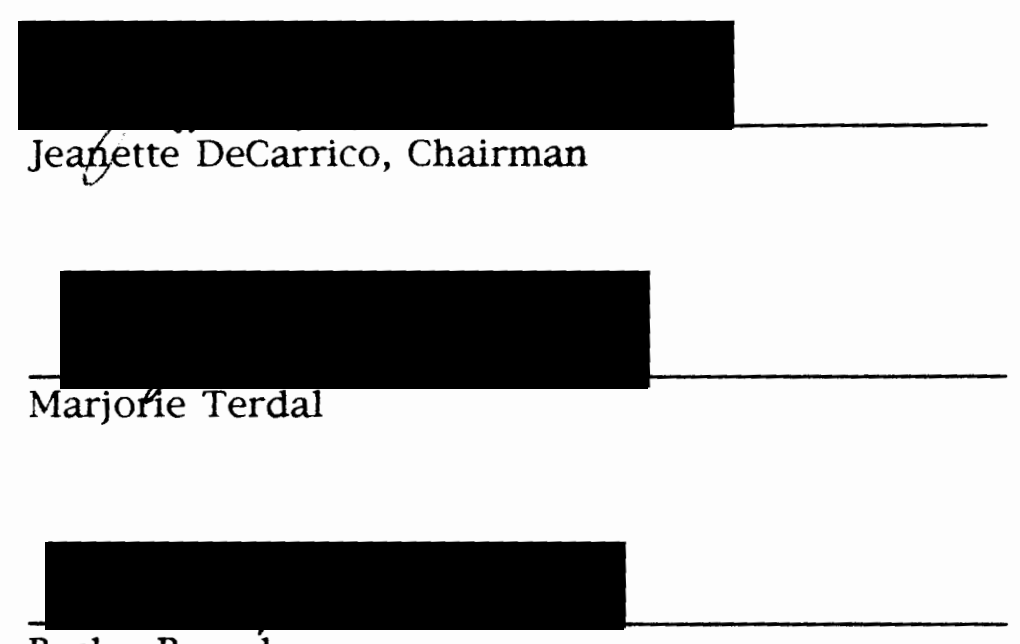

Becky Boesch

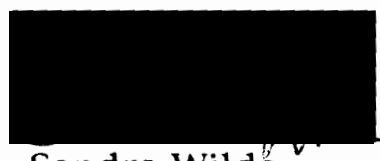

Sandra Wilde

\section{APPROVED:}
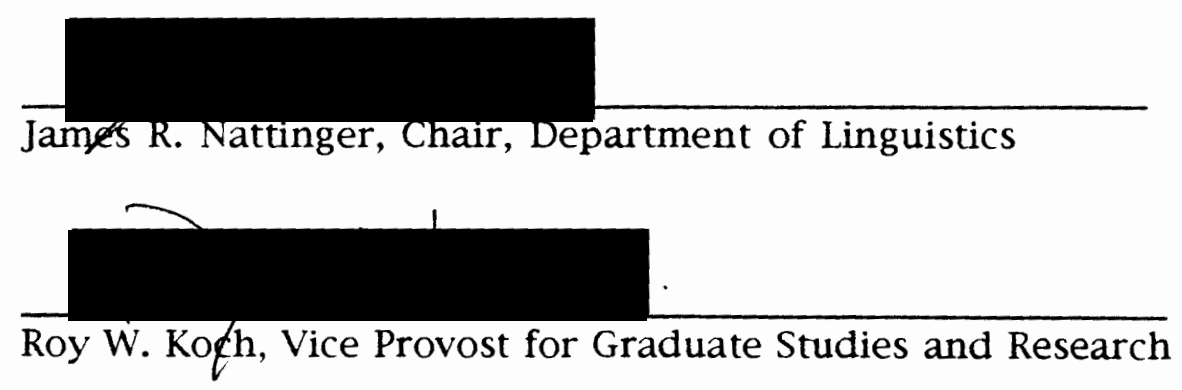


\section{ACKNOWLEDGMENTS}

In expressing my thanks to the advisory committee, I would first like to thank Jeannette DeCarrico who (from the beginning, I think) understood that my ambitions and aspirations for research exceeded my resources and expertise. She patiently but firmly worked with me to develop a study with a realizable goal. Along this same line, I want to thank Marge Terdal who always amazed me with her ability to see the problems or limitations encountered in this study as mere opportunities to consider the alternatives. I would also like to thank Becky Boesch whose daily classroom experience helped to keep in mind the practical concerns of a study of this nature. Finally, I would like to thank Sandra Wilde, whose recommendations for revisions brought greater clarity and cohesion to the descriptive product of this study.

I have been told that the purpose of research at a master's level is not just to prove your theory and achieve significant results. Frequently, the best result that can be hoped for is to lay the groundwork for further research in the area and/or to raise new questions worth exploring. An additional underlying goal of research at this level is to introduce the novice to the research process and help he/she to learn its mechanics. It was the collaborative effort of the members of this committee that accomplished these secondary goals. For this reason, I would again like to thank my advisory committee. Groundwork was laid; good questions were raised, and I learned. 


\section{TABLE OF CONTENTS}

\section{PAGE}

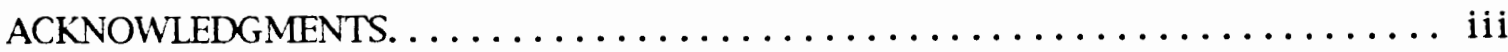

UST OF TABLES $\ldots \ldots \ldots \ldots \ldots \ldots \ldots \ldots \ldots \ldots \ldots \ldots \ldots \ldots \ldots \ldots \ldots \ldots \ldots$

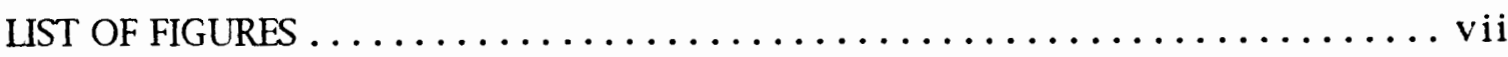

\section{CHAPTER}

I INTRODUCTION $\ldots \ldots \ldots \ldots \ldots \ldots \ldots \ldots \ldots \ldots \ldots \ldots \ldots \ldots \ldots \ldots \ldots$

Statement of the Problem $\ldots \ldots \ldots \ldots \ldots \ldots \ldots \ldots \ldots \ldots \ldots \ldots \ldots$

Statement of Purpose ....................... 4

Statement of Research Hypotheses $\ldots \ldots \ldots \ldots \ldots \ldots \ldots \ldots 4$

I I REVIEW OF THE LITERATURE $\ldots \ldots \ldots \ldots \ldots \ldots \ldots \ldots \ldots \ldots$

Introduction. . . . . . . . . . . . .

Reading: A Psycholinguistic Process . . . . . . . . . . . 10

Schema Theory and the Psycholinguistic Reading

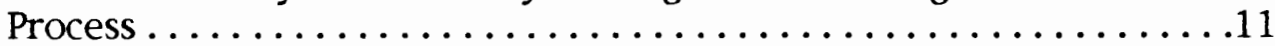

The Relationship of Text Structure to Comprehension. ........13

The Comprehension Process ..................... 16

The Psycholinguistic Reading Model in the

Second Language Classroom ....................... 17

Using Text Organizers to Aid Comprehension $\ldots \ldots \ldots \ldots \ldots 21$

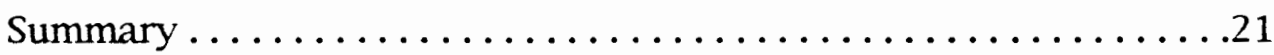

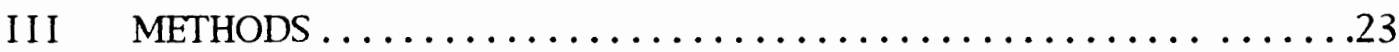

Subjects and Grouping $\ldots \ldots \ldots \ldots \ldots \ldots \ldots \ldots \ldots \ldots \ldots \ldots \ldots \ldots \ldots$

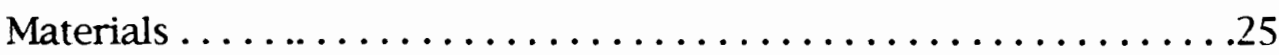




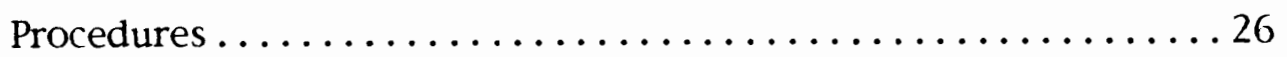

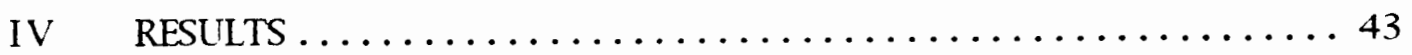

Results of the Pretest........................43

Results of Post-test I ........................44

Results of Post-test II ........................ 45

Other Results $\ldots \ldots \ldots \ldots \ldots \ldots \ldots \ldots \ldots \ldots \ldots \ldots \ldots \ldots \ldots$

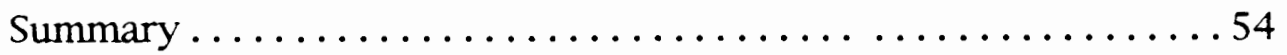

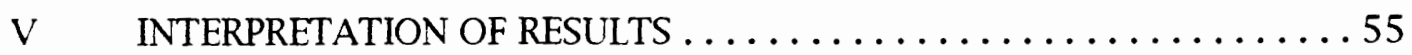

Moderating Variables ..........................55

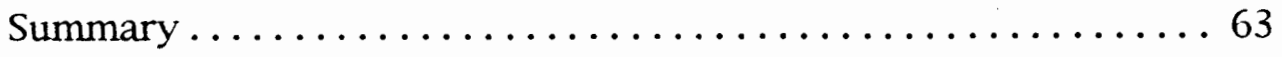

VI SUMMARY, CONCLUSIONS AND RECOMMENDATIONS $\ldots \ldots \ldots \ldots .65$

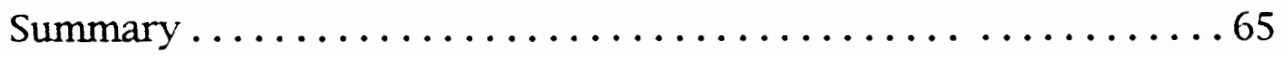

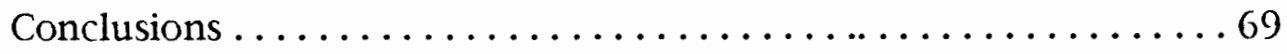

Implications for Teaching $\ldots \ldots \ldots \ldots \ldots \ldots \ldots \ldots \ldots \ldots \ldots \ldots$

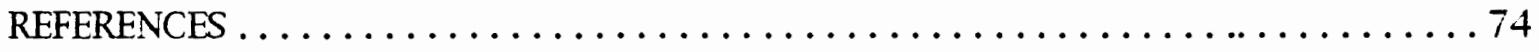

APPENDICES

A PRETEST TEXT, PRETEST INSTRUMENT. . . . . . . . . . . 77

B POST-TEST TEXT, STUDY QUESTIONS, POST-TEST INSTRUMENTS

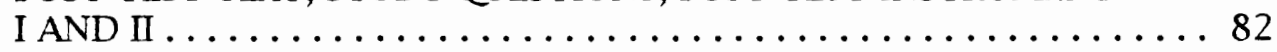

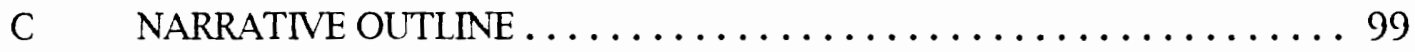

D IRWIN AND MITCHELL "JUDGING RICHNESS OF RETELLINGS"

COMPREHENSION EVALUATION MODEL . ............... 102

E SAMPLE EXAM AND EVALUATION PROCEDURE $\ldots \ldots \ldots \ldots \ldots . . \ldots 5$

F RECONSTRUCTION OF SEMANTIC MAP $\ldots \ldots \ldots \ldots \ldots \ldots \ldots \ldots \ldots \ldots$ 


\section{LIST OF TABLES}

TABLE

PAGE

I Nationality and Years of English Language Instruction By Group. . . . . . . . . . . . . . . . . 24

I I Results of T-test Comparing Mean Scores of Pretest . . . . . . . 43

III Results of I-test Comparing Mean Scores of Post-test I . . . . . . 44

IV Richness of Retellings Criteria $\ldots \ldots \ldots \ldots \ldots \ldots \ldots \ldots \ldots$

V Values Earned by Subject $\ldots \ldots \ldots \ldots \ldots \ldots \ldots \ldots \ldots \ldots \ldots$

VI Assignment of Level Based on Values $\ldots \ldots \ldots \ldots \ldots \ldots \ldots \ldots$

VII Level of Use by Number of Subjects in Each Group . . . . . . . . .48

VIII Results of I-test Comparing Mean Values for Elaborations . . . . .49

IX Results of T-test Comparing Mean Values for Supplementations. .......................... 50

X Results of T-test Comparing Mean Scores from Pretest

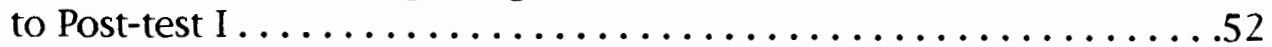

XI Results of T-test Comparing Mean Scores from Pretest

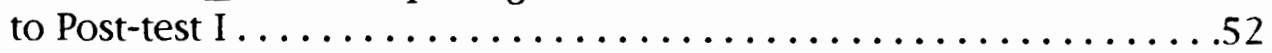

XII Results of I-test Comparing Mean Scores for Irrelevancies . . . .53 


\section{LIST OF FIGURES}

FIGURE

PAGE

1. Research Design Schema ............................

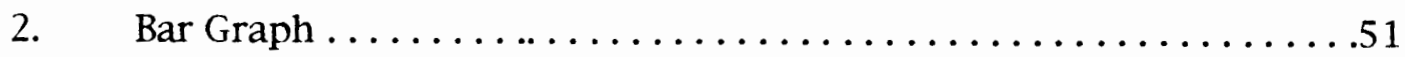




\section{CHAPTER I}

\section{NTRODUCTION}

In the field of second language teaching, there is an ongoing concern to discover teaching techniques to enhance the learning process. Semantic mapping has been used successfully to strengthen vocabulary and enhance reading comprehension in first language classrooms since the early 1980 s. "Semantic mapping" is a strategy designed to graphically display associations related to a central concept or idea. At the present time semantic mapping is being used in second language classrooms as a vocabulary building device as well as a prereading exercise

Studies have shown that students possess schemata, or mental presuppositions, related to text structure and content relationships. Studies have also shown that, when given texts with no apparent order and/or when linguistic cues have been depressed, students will impose an order on the texts based upon their own schematic stores in order to make sense of the text.

Research has also shown that there is a limited set of text structures available which may be used to create an infinite set of possible texts, and that an individual's schemata related to text structure and content relationships may be culturally-biased. In other words, certain cultures may prefer certain structures over others. Consequently, the individual's culturally-biased schemata may interfere with comprehension. 
Traditionally, advance organizers such as narrative outlines and, more recently, story grammars, have been used in first and second language reading classrooms to explicate text structure and/or content relationships. A story grammar, or story schema, as it is sometimes called, organizes the story into basic elements such as setting, plot, and resolution. A story grammar may be very basic, as described above, or more elaborate depending on the story. Advance organizers, as the name implies, are prepared in advance of the reading by the instructor and then provided to the student. They are given to the student to provide an overview of text content and structure, and, as such, have proven useful in helping students understand the organization of the text. However, in the case of second language readers, some population groups may possess textual schemata that are inappropriate to the organization of the text. Because of this, these students might be better served by using a different type of text organizer.

A schematic organizer may be better-suited to these readers because it differs from an advance organizer in two main ways: (1) It is constructed by the instructor and the students in collaboration as the reading progresses, and (2) it provides the student with a graphic display of text content. Because of this, the readers participate not only in the construction of the schematic organizer but, because of the process of construction, they participate in the description of the organization of the text as well.

Schematic organizers vary in form; for example, they can be designed as charts, trees, or diagrams. They are called by several names, most commonly graphic organizers, structured overviews, pattern guides, story maps or semantic maps. For the purposes of this study, the form of schematic organizer under discussion is the semantic map. 
Factors such as individual style, instructional goals and text content dictate the actual mapping process and design. Typically, as each episode of the story is read and discussed, a section of the map is drawn. At the conclusion of the story, the individual sections are then mapped onto a greater map. In the end, the students will have constructed a map of the entire story. Semantic mapping has come under study for use in the second language reading classroom.in recent years. It is hoped that this strategy can aid the reader in achieving a more meaningful understanding of the text by forming an association between text organization and text content.

\section{STATEMENT OF THE PROBLEM}

A review of the literature has shown that readers possess text structure or organizational schemata that are activated during the reading process. In addition, readers assume and rely on certain text organizations and/or logical relationships to be resident in text content. It has also been shown that textual organization is to some degree culturally-influenced and, as such, a second language reader's textual schemata may interfere with rather than aid comprehension. For this reason, second language students may benefit from direct instruction in text organization and content relationships. Semantic mapping is a text organization technique which explicates the relationship between text structure and content. At this time few studies have been done in second language reading classrooms which have measured the effectiveness of semantic mapping as an aid to comprehension. 


\section{STATEMENT OF PURPOSE}

The purpose of this study is to examine the effectiveness of semantic mapping of narrative prose as an aid to recognition comprehension in second language readers. In addition, this study is designed to examine the effectiveness of semantic mapping on the second language reader's ability to make inferences, i.e., supplementations and elaborations, about text content.

\section{STATEMENT OF RESEARCH HYPOTHESES}

1. The use of semantic mapping will result in an increase in recognition comprehension by a treatment group of English as a second language readers using a semantic mapping strategy, as compared to a control group using an advance organizer, based on a combination multiple choice and true/false quiz.

2. The use of semantic mapping will result in greater use of elaboration and supplementation by a treatment group of English as a second language readers using a semantic mapping strategy, as compared to a control group using an advance organizer, based on an analysis of a quiz requiring written responses.

\section{Terms and Definitions}

Several terms have been set out below in order to operationalize them for the purposes of this study.

Comprehension. Two types of comprehension will be measured by this study:

1. Recognition Comprehension. This is comprehension based upon the reader's ability to recall factual detail. This type of 
comprehension is often measured with multiple choice, true and false and short answer test instruments (Irwin, 1991; Devine, 1986).

2. Comprehension. In this type of comprehension, the reader creates meaning through interacting psychologically with the text, which is evidenced by the use of certain thinking skills. For the purposes of this study, those skills to be evaluated will be two types of inferencing: (a) elaboration and (b) supplementation. This type of comprehension is evaluated based on a criterionreferenced test instrument designed to elicit written responses which evidence those thinking skills (Irwin, 1986 and 1991) (see also Devine, 1986).

Elaborations. Elaborations are "generalizations beyond the text" that are relevant to text content (Irwin, 1986, p. 168). Real world knowledge held by the reader as schemata is used in making elaborative inferences about text content. To form an elaboration the reader makes an association between prior knowledge or what he/she knows from real world experience and text content. Often elaborations express a personal opinion, insight or cultural norm. Elaborations may or may not be intended by the author.

Supplementations. Supplementations are inferences based on information implicit in text content. Supplementations are the result of integrative processing and are expressed by the macroprocessing skills used by the reader in comprehending text content. "Integrative processing requires the ability to do such things as identifying pronoun referents, inferring causation and sequence and making other relevant inferences about the total situation being described" (Irwin, 1986, p. 5). Macroprocessing is the "process of synthesizing and organizing individual idea units into a 
summary or organized series of related ideas . . ." (Irwin, 1986, p. 5).

Supplementations are formed based on an understanding of the text at the intersentential level and are intended by the author.

Both elaborations and supplementations are relevant to the text. However, an important distinction between an elaboration and a supplementation is that a supplementation is intended by the author and an elaboration may not be. A supplementation is an assumption and/or paraphrasing based upon common logic and information directly provided by the text content. An elaboration is an assumption that often goes beyond the information provided by the text. Elaborations may express a cultural norm, personal opinion or insight that would not necessarily be commonly held by all readers or the author. An elaboration may also express a bias on the subject's comprehension; however, it does not directly contradict the text. Simply shown, the difference between an elaboration and supplementation appears below.

John was very hungry.

He went to the store.

The store was closed.

Supplementations are inferences that say: (1) "He" in the second sentence is "John." (2) John went to the store because he was hungry; (3) the store was a grocery store, and (4) John intended to buy food when he got there. When the reader makes these inferences, he/she is merely supplementing the information provided by the writer. If, however, the reader inferred that because the store was closed and because John was "very hungry," he was very disappointed, or, taking it further, that he broke into the store and stole some food, the reader would be elaborating on the information provided by the 
writer. These may be relevant inferences (based on what the reader may know personally about John), but there is nothing provided by the writer that would lead to that conclusion (see Irwin, 1986).

Criterion-Referenced Test. This type of test is designed to evaluate an individual's ability to perform a particular mental task. Criterion-referenced tests are based on the assumption that reading comprehension is a complex of separate skills and may be designed to reveal which, if any, of certain mental skills have been used in the reading task (Devine, 1986) (see also Davis, 1983; Kingston, 1970).

Schematic Organizer. A strategy to organize a text based on schematic inter-relationships. "Schematic organizers take the form of diagrams, flowcharts, tables or maps" (Tonjes and Zintz 1991: 308).

Pattern Guide. A pattern guide is a schematic organizer that may take the form of a table, chart or diagram and is used to focus the student's attention on the organizational pattern or content relationships of the text. "Tables, charts, and diagrams that students complete while they are reading are especially effective, because they help the students to visualize the organizational patterns" (Irwin 1986: 65-67).

Semantic Map. A semantic map is a type of schematic organizer. The maps are designed to represent associations between text structure and content relationships. For example, a map designed to express a causal relationship between events in a text will, at the same time, explicate the cause-effect organization of the text. A map is a "diagram of these relationships" (Irwin, 1986: 69). In this respect it may take the same form as certain pattern guides, such as a tree, diagram or flow chart. 


\section{CHAPTER II}

\section{A REVIEW OF THE LITERATURE}

\section{INTRODUCTION}

In recent years, there has been much research regarding the reading process. One of the primary goals of any reading classroom is for students to achieve a meaningful comprehension of the subject text and certainly no less so in a second language classroom. Many of the insights gained from first language reading research are now being adapted to second language learning situations in an effort to aid the less-proficient second language reader. Three findings relevant to this research are that (1) inherent in text content are certain orders and/or logical relationships; (2) most texts are based on one of a small set of rhetorical structures or story grammars, and (3) students both anticipate and rely on the presence of one or more of those structures and relationships in order to readily comprehend the text.

When working with texts, teachers often use a text organizer of some type to explicate structure and content relationships. Most text organizers are prepared in advance of the reading by the teacher and are then provided to the student. Text organizers as such may function as both a pre-reading narrative summary and as a post-reading study guide. Outlines and story grammars are two types of organizers that are typically used in this manner.

Another type of text organizer that has more recently come into the reading classroom is called a schematic organizer. These differ from 
traditional text organizers in that they graphically characterize the organization of the text and are constructed by the teacher in collaboration with the students as the reading progresses. Schematic organizers vary in form and may be called by several names, such as, cognitive maps, structural overviews, graphic organizers and pattern guides, to name a few, depending on their individual specifications. One such device is called a semantic map. Although semantic maps have been used since the early 1980's in first and second language classrooms as vocabulary-building devices, they are just now finding a place in the second language reading classroom as text organizers. They may be used with both expository and narrative prose and can be structured to explicate both text structure and certain content relationships.

Before discussing further the application of semantic mapping of narrative texts, a theoretical overview of the reading process should be established. Reading has been shown to be a psycholinguistic process that relies on both the student's perceptual linguistic skills to decode the text interacting simultaneously with the student's extra-linguistic, conceptual skills. Thus, it involves the schemata of both the text and the reader. Initially, this type of research was done in first language classrooms. However, second language researchers were attendant to the advances made in first language education and have made consistent effort to adapt those findings to the special needs of the second language reader. Second language researchers recognize that the adult, second language learner often possesses the conceptual abilities necessary to comprehend a text but is handicapped by limited linguistic decoding skills, and to some degree, by cultural interference related to conflicting schematic representations. It is hoped that text organizers such as mapping can be adapted to maximize those cognitive 
abilities in which the reader is proficient as well as to help structure corresponding textual schemata.

\section{READING: A PSYCHOLINGUISTIC PROCESS}

\section{Reading as a Psycholinquistic Process}

In 1967 Goodman wrote a seminal article about the reading process which helped to change the way in which educators approached the act of reading. He discussed reading as a meaning-making process, and as such, elevated reading from what had previously been understood as primarily a perceptual, decoding task relying heavily on linguistic skills to a conceptual, meaning-making task relying heavily on cognitive skills. He proposed a new reading model that was based on the reader's extra-linguistic, conceptual knowledge more so than on linguistic knowledge.

Reading is a selective process. It involves partial use of available minimal language cues selected from perceptual input on the basis of the reader's expectation. As this partial information is processed, tentative decisions are made, to be confirmed, rejected or refined as reading progresses. . . . More simply stated, reading is a psycholinguistic guessing game. It involves an interaction between thought and language. Efficient reading does not result from precise perception and identification of all elements, but from skill in selecting the fewest, most productive cues necessary to produce guesses which are right the first time. (Goodman, 1967: 127)

Along with this model came the notion that reading was an interactive process. Interactive in this case means that the higher-level, conceptual, cognitive processing strategies, which came to be called "top-down," and the lower-level, perceptual language decoding skills, which came to be called "bottom-up," functioned interactively and simultaneously during the reading act (Carrell and Eisterhold, 1987; Devine, 1986; Eskey 1986, 1988). As a further 
result there was a shift in the understanding of the nature of the reading act, and a vast body of research was initiated that continues to this day.

\section{SCHEMA THEORY AND THE PSYCHOLINGUISTIC READING PROCESS}

\section{Schema Theory}

Rumelhart (1980) states that "schema theory is a theory about knowledge" (p. 34) and the cognitive processing of that knowledge. He explains that all knowledge can be isolated, theoretically, into separate, abstract units or schemata. Schemata are the "building blocks of cognition" (p. 33) and "they are the fundamental units upon which all information processing depends" (p. 33).

With the statement that all information processing depends upon the presence of schemata, there is a resident notion that schemata do not represent mere facts or data, but also have a functional specification. "Embedded in these packets of knowledge is, in addition to the knowledge itself, information about how this knowledge is to be used" (Rumelhart, 1980: 34).

\section{Schema Theory as a Theory of Meaning}

Rumelhart (1980) postulates a schema as a larger, complex, dynamic, structure which represents all knowledge of all types from all sources that is stored in memory; all of which is encoded, jointly and severably, with the knowledge of how to use that knowledge. As a consequence, a schema theory represents a theory of meaning.

A schema contains, as part of its specification, the network of interrelations that is believed to normally hold among the constituents of the concept in question. A schema theory embodies a prototype theory of meaning. That is, inasmuch as a schema 
underlying a concept stored in memory corresponds to the meaning of that concept, meanings are encoded in terms of the typical or normal situations or events that instantiate that concept. (Rumelhart, 1980: 34)

\section{The Acquisition and Function of Individual Schema}

A schema is the mental property of an individual. An individual's schema, however, does not exist in a static state; it changes. As people have more experiences and acquire more knowledge, they refine, reshape, correct and restructure their schemata accordingly (Devine, 1986; Rumelhart, 1980).

Based on the above, an individual's schema is a dynamic, knowledgegenerating structure. First, a schema functions to make an appropriate fit of incoming data to data previously stored and conceptually represented in order to make meaning (Rumelhart, 1980), and second, the acquisition of schemata is ongoing and an individual's schema tends to be self-correcting and able to restructure itself (Devine, 1986). Therefore, a schema theory implies that a schema is not just a passive recipient of data., but rather, it processes incoming data and governs corresponding interpretations of that data, i.e., conceptual representations, as well.

\section{Schema Theory as Component of Reading Comprehension}

Schema theory as a component of psycholinguistic reading theory is based on the notion that there is a schematic interaction between reader and text that facilitates comprehension. It is also based on the notion that, while reading, there are two levels of information processing that are occurring simultaneously. One level has to do with the cognitive activities necessary to achieve comprehension, i.e., evaluation, interpretation, prediction and inferencing, and the other has to do with the decoding activity performed on the incoming linguistic data, i.e., "the graphonic, lexical, syntactic/semantic, 
and rhetorical patterns of a language" (Devine, 1988: 260)(see also Anderson and Pearson, 1988; Carrell, 1984, 1985; Carrell and Eisterhold, 1987; Devine, 1986; Eskey, 1986, 1988; Goodman, 1967).

\section{THE RELATIONSHIP OF TEXT STRUCTURE TO COMPREHENSION}

In developing his psycholinguistic reading model Goodman (1967) relied heavily on the role that the reader's real world knowledge played in reading proficiency. Other researchers, however, have pursued the role that linguistic knowledge, and particularly, text structure, plays in reading comprehension.

\section{Text Structure and Comprehension}

In 1980 Goetz and Armbruster reviewed the literature in an attempt to examine "how variations in text structure influence the way people read, comprehend and remember text" (1980:201). They initiated their research on the premise that because reading always involves text, there must be a correlation between text structure and comprehension. Although at that time Goetz and Armbruster found "the existing literature is almost embarrassingly meager and rudimentary, given the import and complexity of the area" (p. 201), they did form an important conclusion about the importance of text organization and its relationship to memory. "[T]hose [texts] that are more highly organized or more congruent with the reader's knowledge and expectations are better remembered" (p. 216).

Goetz and Armbruster (1980) also investigated the relationship between text disorganization and the reader's ability to achieve comprehension. As a result, they adopted what they called a "constructivist view" (p. 214). The 
constructivist position is that meaning is not simply inherent in the text, but that a reader, when given disordered texts and/or texts with displaced or deficient linguistic cues, will insert words, sort information, organize data, and impose structure, in order to make sense of the text. While not saying that knowledge of text structure itself is necessary to make sense of a text, they did conclude that "the knowledge, expectations and purposes of the reader interact with the text to determine the interpretation and the structure of the memorial representation" (p. 217) (emphasis mine). The importance of their findings to this research is that, (1) reading is a psychologically interactive process between text and reader, and (2) text structure, whether inherent or applied, seems to be a necessary component of comprehension, because, if the text lacks it, the reader will form a structured memorial representation by default based on his/her existent schematic stores.

The Text Structure of Expository Prose. Within the context of expository texts, students have two types of prior knowledge structures, or schemata, that they bring to the reading task. In addition to the content schema (general world knowledge and experience, etc.), they also possess formal schemata (knowledge of the formal, rhetorical organizational structures of different types of texts). Further, readers expect that organization to have certain logical orders or relationships (Anderson and Pearson, 1988; Carrell and Eisterhold,1987; Carrell 1984, 1985).

Carrell and Eisterhold (1987) discuss types of rhetorical organization that have been isolated and identified: collection (list); causation (cause and effect); response (problem and solution); comparison (comparison and contrast), and description (attribution). They state that each of the above 
types represents "a different abstract schema of ways writers organize and readers understand topics" (Carrell and Eisterhold, 1987, p. 223).

The Text Structure of Narrative Prose. In their investigation of the relationship of text structure to comprehension, Goetz and Armbruster also cited a study by Stein and Glenn (1978) which investigated the idea of prototypical, underlying text structures of narrative prose called "story grammars" (Goetz and Armbruster, 1980, p. 212). Simply stated, story grammar is a term used to represent a limited set of structures common to an infinite set of possible stories. The basic assumptions upon which story grammar models are based are (1) stories have internal structure; (2) the structure is both hierarchical and based upon certain logical relations, and (3) the structure of the story corresponds to the way people comprehend and store information.

\section{Teaching Text Structure as an Aid to Comprehension}

Goetz and Armbruster, based on their 1980 review of the literature, did not conclude that evident text structure or knowledge of text structure was essential to comprehension. However, they did recognize the role the reader's unconscious use of schemata for text structure played in their ability to comprehend a text. They stated, "[w]e are convinced that future research on the psychological correlates of text structure will make real progress only when this interaction, rather than the structure "in" the text becomes the object of the study" (p. 217). In other words, they concluded that future studies should be directed toward the psychological interaction of the reader upon the text, rather than focusing on knowledge of text structure itself. (For a thorough examination of studies relied on by Goetz and Armbruster, 1980, see Meyer, 1977 and Stein and Glenn, 1978; for studies relied on by Carrell and 
Eisterhold, 1987, see Meyer 1975 and 1977; Meyer, Brandt and Bluth, 1980; and Meyer and Freedle, 1984).

\section{THE COMPREHENSION PROCESS}

\section{Comprehension as anInteractive Process}

Irwin (1986) recognizes that comprehension is primarily an interactive, conceptually-based task and works from that premise to construct a five-part overview of the processes involved.

1. Microprocesses: understanding and selectively recalling idea units in individual sentences;

2. Integrative processes: understanding and inferring the relationships between individual clauses and sentences and inferring causation and sequence

3. Macroproccesses: synthesizing and organizing ideas around more general summarizing concepts to develop an overall organizational pattern for the text:

4. Elaborative processes: making inference beyond the text, and

5. Metacognitive Processes: developing one's own strategies to effect comprehension and long-term recall of text, i.e., study strategies.

Irwin's overview isolates the cognitive skills active in the comprehension process and emphasizes its psycholinguistic nature. She adds that these processes are necessarily interactive. She concludes that when students understand the organization of the text and are able to develop an overall organizational pattern for the text they are better able to recall factual detail as well. "Research has repeatedly shown that readers who use the author's organization pattern to organize their own memory of the passage 
actually recall more than those who do not" (p. 60) (see also Gerhard, 1975; Meyer, 1977; Meyer, Brandt \& Bluth, 1980; and Stein and Glenn, 1978.)

THE PSYCHOLINGUISTIC READING MODEL IN THE SECOND LANGUAGE CLASSROOM

Although the psycholinguistic reading model has become accepted as a viable model of the reading process, it is a model, not a method. Specialists in second language reading, Clarke and Silberstein (1987), state that there is no "psycholinguistic method" (p. 234), only "the insights it provides into the reading process" (p. 234). In their opinion, the most valuable of these insights are: (1) the reader does not use all the linguistic information on the page, only the most productive cues; (2) the reading act is both process (comprehending) and product (comprehension); (3) reading is an interaction between thought and language, and the reader brings an appreciable amount of information to the task, and (4) the reader builds his/her conceptual world by adding information to the text, and that the text must be semantically complete, or meaningful, for the reader to achieve comprehension.

\section{Developing Methods for the Second Language Classroom}

In his discussion Eskey (1988) states that the purpose of reading remains the same whether readers are attempting to read in his or her first or second language, that is, to achieve comprehension. In addition, while no interactive model can determine what specific mix of skills should be employed, i.e., bottom-up or top-down, "a teacher must develop a sensitivity to what his students know and what his students can do and adapt his approach to the level of the students he is trying to help" (Eskey, 1988, p. 20) 
There is a direct correlation between the problems of the second language reader and the very nature of the reading act itself. Because efficient reading relies on a minimal number of linguistic cues to activate what are otherwise cognitive processes, and it is those linguistic cues that the second language reader often misses when engaged in the reading task, it is reasonable to assume that if second language readers can be trained to minimize their reliance on linguistic cues and maximize their reliance on certain cognitive strategies, the proficiency of the second language reader will increase (Carrell 1984, 1985) (see also Devine 1988; Eskey 1986 and 1988; Grabe 1986).

Carrell (1984) discusses her review of the literature wherein she investigate the relationship between text structure and reading proficiency. She cites studies from first language classrooms that yield evidence that students who organize their recalls according to a text's organization remembered far more content. Based on her own study of second language learners, which showed that second language readers often miss important, text-embedded linguistic signals, Carrell states that they may need to be explicitly taught text structures and encourages instructors to incorporate such instruction into their reading curriculum (see also Meyer 1977; Meyer, Haring, Brandt \& Walker, 1980; and Meyer and Freedle, 1984).

\section{Culturally-based Differences in Text Schema in Second Language Learners}

The reading process of the second language learner differs in certain respects from that of the first language reader. A major difference relevant at this point has to do with the culturally-based schematic stores the second language learner may possess for text structure. Carrell (1985) cites a study in 
which English speakers were given a text written with a typical Japanese rhetorical structure. The findings showed that the typical Japanese text structure was difficult for English-speaking natives to process and more importantly, it was "extraordinarily problematic" for English speakers to approximate the contents in delayed recall (p. 729). The importance of this finding is, that since not all structural representations are present in the schematic stores of all readers, (1) there may be cultural interference activated by the reader's resident schemata, and (2) second language learners may require explicit instruction to aid in the acquisition of appropriate text schemata (see also Carrell and Eisterhold, 1987; Devine, 1988; Grabe 1986).

\section{USING TEXT ORGANIZERS TO AID COMPREHENSION}

Tonjes and Zintz (1981) state that knowledge of the way material is organized and the corresponding "pattern of thought" (p. 323) may help students better comprehend the material. Various forms of text organizers are available and some have been used for years in the reading classroom. Of those, the advance organizer has been most commonly used. Advance organizers, as the name implies, are prepared in advance of the reading and provided to the student. As mentioned previously, narrative outlines and story grammars fall into this category. Diagrams, flowcharts, and cognitive maps fall into this category as well if they are prepared independently and provided to the student rather than being constructed cooperatively by teacher and student (Tonjes and Zintz, 1981). 


\section{Advance Organizers Compared to Schematic Organizers}

Text organizers are typically broken down into two categories: advance organizers and schematic organizers. While both types provide a basis to teach text structure, schematic organizers differ fundamentally from advance organizers in that they provide a graphic overview of the text and are prepared in collaboration with the students and the instructor.

Semantic Maps. Semantic maps fall into the category of schematic organizers. The actual mapping procedure may vary according to the individual teacher's objective, the particular text and the proficiency level of the students. The procedure usually involves a post-reading discussion session in which students are asked to verbalize events from the text from a general to a more specific context. This phase of the procedure provides students with an opportunity to engage in a mental activity which uses stored prior knowledge as well as information from the text. In this way the student is able to form relationships between ideas or concepts, characters and the succession of events under the guidance of the instructor. For example, a general concept may be "greed." The student might be asked to construct a cause and effect relationship between this abstraction and certain events in the text. The student then categorizes text information and forms a causal link between and among the events. Ultimately a pattern is developed that explicates the relationship between the larger, more general concept and the events of the text (see Heimlich and Pittleman, 1986; Irwin, 1991; Tonjes and Zintz, 1981).

\section{Using Semantic Maps in the Second Language Classroom}

Carrell, Pharis and Liberto (1989) discuss the viability of semantic mapping in the second language classroom. Their support is based on its 
reported success in first language classrooms where Reutzel (1985) reported success in explicit training in story maps with both expository and narrative texts. In his study the group which received instruction in story mapping recalled significantly more of both narrative and expository texts than did the control group which used the directed reading approach.

According to Carrell, Pharis and Liberto (1989), second language students may need to be taught strategies to recognize text structure in order to improve comprehension.

Strategy research has indicated that less competent learners are able to improve their skills through training in strategies evidenced by more successful learners. The same is true of reading strategies: Less competent readers are able to improve through training in strategies evidenced by more successful readers. (Carrell, Pharis and Liberto, 1989: 648)

They initiated their own study using semantic mapping and another approach called "experience-text-relationship" and were encouraged by the results. "Our results show that metacognitive strategy training in semantic mapping and in the experience-text-relationship method are effective in enhancing second language reading" (p. 668). They conclude their report by encouraging instructors to include strategies such as these in their own classrooms to aid the second language reader.

\section{SUMMARY}

Semantic mapping holds promise for the second language reading classroom because it provides readers with a conceptually-based, organizational strategy which can help to categorize information and form associations between text structure and/or certain content relationships. 
Semantic mapping uses both the reader's schemata and text content. Because a semantic map is prepared in collaboration with the teacher, the student can be guided to construct both a useful and efficient conceptual overview of the text. 


\section{CHAPTER III}

\section{METHODS}

The study was conducted at a community college using students preassigned to two different reading levels on the basis of pretesting and oral interviews as required for admittance by college administration. This chapter discusses the subjects and grouping, methods and materials, and overall study design and procedures.

\section{SUBJECTS AND GROUPING}

All subjects were students attending English for Non-Native Residents ("ENR") reading classes at a community college. The subjects were preplaced in either a level III or a level IV reading class prior to the commencement of this study. Placement at these levels was based on the results of the subjects' Michigan Test of English Language Proficiency scores or demonstrated language proficiency by oral and written interview, and/or previouslycompleted successful ENR reading coursework. The treatment group was formed from students who had placed at level IV and the control group was formed from students who had placed at level III. Because students were assigned to each classroom based on the results of admission pretesting or prior coursework, a second pretest was considered necessary to determine comparability between groups for the purposes of this study. 
Twenty-seven subjects participated in the study. The sample sizes were 14 for the treatment group and 13 for the control group. All students consented to participation.

The subject profile for this study is that of an adult, educated and literate in his/her first language. Both groups are formed from diverse immigrant populations with varying backgrounds in English language instruction (see Table I below).

TABLE I

NATIONALITY AND YEARS OF ENGLISH LANGUAGE INSTRUCTION BY GROUP

\begin{tabular}{|c|c|c|}
\hline \multicolumn{3}{|c|}{ CONTROL GROUP } \\
\hline Nationality & Number & Years of English \\
\hline Chinese & 2 & 4,4 \\
\hline Ethiopian & 1 & \\
\hline Japanese & 1 & .05 (in US) \\
\hline Korean & 2 & 6,8 \\
\hline Lebanese & 1 & 1 \\
\hline Micronesian & 1 & 1.5 \\
\hline Vietnamese & 4 & $.05,2,2,2$ \\
\hline Nationality & $\begin{array}{r}\text { TREA } \\
\text { Number }\end{array}$ & Years of English \\
\hline Chinese & 2 & 4,7 \\
\hline Japanese & 2 & 5,7 \\
\hline Kuwaiti & 2 & 1 (in US), 15 \\
\hline Lebanese & 2 & 1,1 \\
\hline Soviet & 1 & 3 \\
\hline Vietnamese & 4 & $1,1,2,3.5,5$ \\
\hline
\end{tabular}

\section{Time and Location}

The study was conducted in a regular classroom setting. The treatment, as applied in this study, obliged a methodical progression through the text that required three classroom hours to complete. The time period for reading, 
explication and review of the text was 2.5 days for the control group and 3.5 days for the treatment group. Post test I was taken by both groups during the last half of the classroom hour. Approximately 30 minutes was allowed for post-test I. Post-test II was given the following day, and the subjects were allowed the full classroom hour to take the test.

\section{Instructors}

Because both groups consisted entirely of ENR students pre-placed by college administration in two different reading levels, the two groups also had two different reading instructors assigned previous to the commencement of this study. The researcher/instructor taught the treatment group, and a different regularly-assigned instructor taught the control group. Because the instructor/researcher was not able to observe the collaborating instructor, the class sessions were taped onto audio cassette for the researcher's review.

\section{MATERIALS}

The texts and test instruments and other pertinent materials are listed below and then discussed individually.

The materials used in the study:

1. Pretest text and test instrument (treatment and control group);

2. Study text and post-test instruments I and II (treatment and control group;

3. Text study questions and reading aids (treatment and control group);

4. Outline of study text (control group);

5. Map schema of study text (treatment group), and

6. Audio cassette recorder (control group). 
The text used for the pre-test was "The Midnight Visitor," by Robert Arthur. It was found in the textbook, Reader's choice. This textbook is a reading coursebook designed for English as a second language learners (see Appendix A). The text used in the study was "Rope" by Katherine Ann Porter. It was found in the textbook, Outsiders: American short stories for students of ESL. The textbook is a reading coursebook designed for English as a second language learners (see Appendix B). It was preselected by college administration for use as the regular coursebook for ENR Reading Level III. Each short story has an accompanying set of study questions. Each story has an accompanying glossary, informal speech and standard vocabulary sections which isolate and restate idioms, colloquialisms and non-standard speech found in text content. The researcher/instructor and the other instructor collaborated on the selection of the story to use for the study. The narrative outline provided to the control group prepared by the researcher/instructor was reviewed and approved by the control group instructor. The narrative outline was given to the control group to provide an overview of text content (see Appendix C).

\section{PROCEDURES}

Both instructors were concerned that each group achieve a meaningful comprehension of the text. In addition, both instructors were concerned that the purposes and goals of the study were met. The instructors attempted to conform their approaches and certain aspects of text explication in an effort to reasonably approximate these concerns. 


\section{Similar Procedures Related to Text Explication}

The instructional approach used was question and response. That is, the explication of the text was based upon responses elicited from the subjects and ensuing discussion. In preparation for discussion of story content, both instructors reviewed the following topics: (1) story setting, (2) time period, (3) the main characters, and (4) the circumstances. In addition, both instructors discussed the author's writing style, because, in this story there is no direct dialogue. All communication between the two characters is written in the form of indirect speech. Because this form may be difficult for non-native speakers to follow, the difference between direct and indirect speech and how the use of indirect speech contributes to the overall tone of the story and purpose of the author were discussed with both groups.

Both instructors' explications included some open discussion regarding extra-textual issues relevant to the story content. Extra-textual in this case means discussion about real world events or real world experience as relevant to the text content. (For an example, see the control-group instructor's explanation of husband/wife stereotypes in American culture, as set out in the transcriptionabove.)

\section{Control Group Procedures}

Before commencing explication of the text the control group instructor gave each subject a narrative outline of the text to use as a text organizer and review guide because it is the most commonly used text organization device in the second language reading classroom. Then the control group was asked to preread the text in preparation for the next class session. 
After the introductory lecture and discussion regarding the story setting, characters, circumstances of the plot and author's style, as mentioned above, the instructor began explication at Scene I. In general, the progression through the text was on a scene-by-scene basis, that is, the discussion commenced at Scene I and closed at Scene X. Although the text explication moved forward on a scene-by-scene basis, occasional digressions in text occurred as relevant to the topic. For example, while discussing Scene V, the conversation moved back to related incidents in Scenes II and III before returning to Scene V. In order to show the control-group instructor's approach and to give examples of the backward digressions, segments of the instructor's explication have been set out below.

In preview, a subject has read paragraph 1 from Scene $V$ aloud. The ensuing discussion concerns the nature of the issues between the characters; that is, how they think about each other, and what their roles seem to be. The instructor has referred briefly (without asking subjects to refer to their texts) to an incident from Scene IV wherein the wife has accused the husband of leaving his tools laying about. Then the instructor refers the subjects back to paragraph 1, Scene $V$ and asks the group a series of questions which are supplemented by excerpts he reads from the text:

He [the husband] feels defensive, right? She was telling him all these things he was doing wrong that were affecting their relationship. He was thoughtless; he was only thinking of himself; all this stuff, and he was getting defensive -- he said things like, "Did she realize she was making a complete fool of herself," and "What did she take him for -- a three year old idiot?" And then that's when he made the comment that "what she needed was something weaker than she was to heckle and tyrannize over. He wished now that they had a couple of children she could take it out on. Maybe he'd get some rest." 
The instructor then explains:

She saw him as this thoughtless husband, who only thought of himself and he saw her as this woman, who, all she did was try to "heckle and tyrannize him."

Instructor explains the terms: "heckle and tyrannize." The instructor then commences an extra-textual explanation regarding the husband/wife stereotype in American culture that this couple represent, and where it is found: in stories and in sitcoms on television, movies, etc. Instructor then continues discussion regarding how these traditional roles are now changing, and how women working outside the home in recent years have contributed to the change. Discussion also ensues regarding how long the couple have been married and what their expectations of each other in terms of roles seem to be.

Instructor then refers the subjects back to Scene II and continues the discussion with a series of questions. In the following transcriptions the responses to the questions have been ommitted:

Here's another example. What did he do to the eggs? He also brought home the eggs and what happened to them? Why did the eggs break? What was on the top of the eggs, that she saw? What did he say about the eggs? Did he admit that he put the rope on there? Where did he say the rope was? Who did he blame?

The instructor then reads from last paragraph of Scene II and first paragraph of Scene III and explains to group:

He didn't take the blame for himself. He was again defensive and he refused to admit that he did anything wrong, right?

Instructor then refers subjects to Scene III, paragraphs 2 and 3. They read briefly (silently) and then he asks them a series of questions: 
And what did he tell her she could do with the eggs? Scramble them and have them for what? For the next day? or for what? For dinner. Any why couldn't she do that? Yeah, she already had the steak for the dinner. Well, why couldn't she just postpone the steak and have that tomorrow? Right, they didn't have any refrigerator; they had no ice. What did they have here, by the way? Did they have running water? Did they have electricity? They didn't have any of that stuff. This is a rural farmhouse. So, what would happen if she left the steak for another day. Yes, it would spoil. Right. So, you know, again, this is another example of his thoughtlessness, see. He was saying, "you can do this, and she was saying, "No, because the steak goes back and I can't leave the eggs."

Instructor then asks the subjects a series of questions about eggs:

He said, " well you could leave them for breakfast." Well, what would happen to the eggs? If you leave the eggs in a bowl overnight, what would happen to them? Yeah, they'd spoil too. So, again, this was another example of his thoughtlessness.

The Instructor then refers subjects back to Scene $V$ and reads from paragraph 2, supplementing the text excerpts with brief comments:

"She reminded him again that he had forgot the coffee and had bought a worthless piece of rope" And then talked to herself and got angry. "And when she thought of all the things they actually needed to make the place even decently fit to live in, well, she would cry, that was all." It made her even more angry when she thought about what he had done; what he allegedly had done. O.K.

A second, shorter example of the control group instructor's use of text digression occurs during explication of Scene X. During discussion of this scene, the subjects are referred back to paragraph I of Scene VII. The discussion of Scene $X$ opens regarding the setting, the changed attitudes of the characters, and their conversation. The instructor then asks the subjects to 
find and read Study Question 19, "Inference." He then reads it aloud and asks a question:

What inferences might we draw from the odd little passage: 'He put his arm around her . . . for the Ootsum-Wootums'? Does anyone know what that is?

The Instructor then refers the subjects to paragraph 4 of Scene X. They read it briefly (silently). Then the instructor reads it aloud to the subjects. The instructor asks the subjects to read the glossary definition of the term "Ootsum-Wootums." The instructor then returns to Scene X and commences explication:

What was going on here? What was happening? Ah, very good. How many of you saw that? He patted her stomach and made some baby talk. What was she? What was her condition? Yeah, she was pregnant. Yes, she had wanted some milk of magnesia. Remember where she asks for milk of magnesia?

Instructor then refers subjects to Scene VII, paragraph 1; he reiterates briefly the circumstance of the episode, then he reads excerpts from text to supplement his explication of Scene X.

She had an upset stomach and she wanted some milk of magnesia. She wanted him to "go back to the village and get her coffee," but she also said, "and a bottle of milk of magnesia from the drugstore." So, she also wanted some milk of magnesia, which is used for upset stomach, and those of you who have been pregnant know that, you know, that's a common occurrence. Right?

\section{Treatment Group Procedures}

Before commencing explication of the text, the treatment group was asked to preread the first section of the text to be discussed, that is, scenes I, II, and III, in preparation for the upcoming class. At the beginning of the class 
session the instructor/researcher informed the group that they would be using a technique called "semantic mapping" during discussion of the text. In order to provide the subjects with an idea of what a semantic map is, the instructor brought to class sample maps of a different story. The subjects were advised that one of the purposes of the map would be to show the causal relationship between events of the story. (In this case, arrows were frequently used to show this relationship.) The instructor defined the term "cause and effect" as an organizational pattern. The instructor then explained how the mapping process would be done. (1) The instructor would work at the board during the discussion of the story writing down their responses. (2) As each scene was reviewed, the subjects would identify the important events and then the group would construct a short summary of the scene. (3) As the mapping progressed the subjects were to draw a similar map in their. notebooks because at the end of the story, they would be expected to turn in their own semantic map, that is a map of the entire story. (4) The instructor explained to the subjects that they did not have to construct their map exactly like the one done in class. They could use any format they chose, but that it should show the causal relationship or connection between the major events of the story.

The Instructor/researcher commenced discussion of the text by drawing a rectangular box on the blackboard. The box was labeled Scene I. After a preliminary discussion of characters, setting, and author's style, etc., the instructor opened the mapping session by asking questions about the scene, such as, "Where was the wife when the husband came home?" "Why was she there?" "What did she ask him?" As the subjects responded, the instructor wrote their comments and/or detail from the text on the board in 
whole or in part. As necessary to the discussion, the instructor asked subjects to read excerpts from the text. Often, as the material was collected on the board, short arrows were drawn between certain units of information. For example, two units of information from Scene I such as, "He said, to hang clothes on," and "She said, they already had a fifty foot line," would be connected by a short arrow. At the end of the discussion of the scene, the subjects constructed a short summary of the main events using the written material on the board. The summary was then written into the box and an arrow was drawn from the box labeled Scene I to a new box labeled Scene II. (After the summary was constructed by the subjects and the instructor had written it in the box, the material previously elicited and written on the board was erased in order to make room for new material from Scene II.) The remaining nine scenes of the story were mapped in a similar manner. The summaries typically consisted of three to four short sentences. (See Appendix F for a reconstruction of the semantic map constructed during the study.)

The Mapping process. Semantic mapping is a categorical structuring of information into graphic form. The semantic mapping procedure is a collaborative effort between the instructor and the subjects. Typically, the procedure includes a brainstorming session in which subjects are asked to verbalize associations to a certain topic as the teacher maps (categorizes) them on a chalkboard. The actual mapping process may vary according to the individual instructor's materials and objectives. The mapping application used in this study was designed to accommodate the instructor's underlying goal of teaching the organization of the text as well as explicating story events. In doing so, it was hoped the subjects would be able to form a semantic association between story events and the organization of the text. For a better 
understanding of the application used in the classroom, it has been reduced to a three-step procedure.

1. Directed brainstorming. The first purpose of this step is to collect information. The second purpose is to organize that collected information in such a way that the subjects are able to see the causal link between events. Directed brainstorming, in this case means the offering of text detail, relevant ideas and opinions by the subjects in response to questions posed by the instructor or as they normally arise from discussion. The subjects respond either from free recall or from excerpts of text. As the subjects supply information, it is written on the board in whole or in part by the instructor (as appropriate to time and space available). Most material on the board is written in the form of short phrase quotes from text or brief sentences. Occasional short comments or opinions about the characters or events made from subjects are written on the board as well.

2. Review. The purpose of this step is to survey the information on the board in order to construct an adequate summary of the scene. In this step the subjects must decide what is important information and what may be ommitted. As the subjects evaluate the material, the instructor checks or otherwise marks important comments or details and information not needed is lined out or erased.

3. Summarizing. In this step the subjects verbalize a summary of the scene by using the information remaining on the board. The instructor facilitates the expression by supplying linking terms or phrases, punctuating, etc. The typical summary consists of three or four short sentences.

A fourth step is also part of the mapping process, but it is independent. That is, the subject does this step without the help of the instructor. The 
purpose of this step is to produce a graphic overview of the events of the story that helps to visualize the organizational pattern of the text. In this step each subject constructs a map of the entire story based on his or her observations and participation in the classroom procedure supplemented by lecture notes and/or text.

\section{Differences in Procedures Related to Text Explication}

The different techniques used during text explication necessitated variances in the question and response approach to text explication. Both instructors followed the natural order of text events, that is beginning discussion at Scene I and closing discussion at Scene X. However, as stated previously, the control group instructor digressed as appropriate in order to supplement the idea or topic under discussion. For instance, in the above transcript the class is in Scene $\mathrm{V}$ discussing the couple's relationship, their basic natures and their attitudes toward each other. Because the notion of the husband's "thoughtlessness" is being discussed, the instructor moves backwards to other scenes to make that point.

On the other hand, the treatment group instructor followed the sceneby-scene sequence of events. This is because the underlying purpose of text explication was to show the causal nature of the events of each scene. Very little reference was made to other scenes during the explication of a particular scene, and there was no directed reading into another scene.

A second difference related to procedures resulted in part from the materials used in the study. Both groups used a text organizer to survey text content. The control group was provided with an advance organizer in the form of a narrative outline. This outline provided the reader with a summary 
overview of text content in chronological sequence. The treatment group constructed a semantic map. Like the narrative outline, the completed semantic map provided a summary overview of the text content. Like the narrative outline, the semantic map provided a summary overview consistent with text organization. However, there is an essential difference between the two types. The narrative outline was prepared in advance by the instructors and provided to the control group before explication commenced. It was not a product of their explication experience. The mapping process, however, required that the treatment group participate in the process of summarization. As such, the map was a product of their text explication experience.

Independent and Dependent Variables

The independent variable is the semantic mapping technique. The dependent variables measured by this study are (1) recognition comprehension and (2) comprehension based on certain thinking skills related to comprehension, i.e., elaboration and supplementation.

\section{$\underline{\text { Research Design }}$}

The study was a quasi-experimental, intact-group design. This design was necessitated because of the lack of random assignment to each group. Because both groups were formed from diverse immigrant populations with varying backgrounds in English language instruction, a pre-test was administered to each group before the study commenced in order to assess each group's reading ability.

Both groups were post-tested with the same two test instruments. Between-group post-test scores were used to determine the effectiveness, if any, of the treatment. Post-test I was designed to measure the level of 
recognition comprehension. Post-test II was designed to measure certain thinking skills related to comprehension, i.e., elaboration and supplementation. Figure 1 below shows the design schema.

\begin{tabular}{|c|c|c|c|c|}
\hline \multicolumn{5}{|c|}{ Research Design Schema } \\
\hline I & Control Group & $\mathrm{X}$ & $\mathrm{O}$ & $\mathrm{X} 1, \mathrm{X} 2$ \\
\hline $\mathrm{R} / \mathrm{I}$ & Treatment Group & $\mathrm{X}$ & $\mathrm{T}$ & $\mathrm{X} 1, \mathrm{X} 2$ \\
\hline
\end{tabular}

Figure 1. "I" stands for Instructor. "R/I" stands for Researcher/Instructor. "X" stands for the pretest. "X1" stands for the post-test I. "X2" stands for the post-test II. "T" stands for the treatment; " $\mathrm{O}$ " stands for no treatment.

\section{Test Instruments}

Pre-test. The text and test instrument were pre-selected by the control group instructor as a diagnostic instrument to evaluate the control group's reading ability. The treatment group instructor/researcher used the same text and test instrument previous to commencing the experiment. The pretest was necessary in order to assess between-group compatibility based on reading ability. The pretest instrument was a short answer quiz (see Appendix A).

Post-tests. Both groups received the same two post-tests. Post-test I was designed to measure recognition comprehension, i.e., recall of factual data, by a combination multiple choice and true/false test instrument. There were 15 questions. Post-test II was a criterion-referenced test instrument designed to elicit written responses about text content in order to measure certain factors of comprehension. The subjects were provided with the specific text on the test instrument that was to be read and referred to in forming their written responses. The test text was two excerpts from the short story. The test consisted of eight questions (four for each text) (see Appendix B). 


\section{Post-test Validity}

Post-test I. Post-test I was a combination multiple choice and true/false test instrument. The questions on this instrument were written by the treatment group instructor/researcher. The test instrument was reviewed and approved by the control group instructor before being used.

Post-test II. The control group instructor and the treatment group instructor collaborated in the design and construction of the test instrument, specifically, the text to be used on the test instrument, the corresponding questions and the test format.

\section{Procedure for Evaluating Data Collected by Post-Test II Instrument}

Post-test II test instrument was designed to elicit inferences about text content which could be evaluated based on a strategy designed by Irwin (1986) (and adapted for the purposes of this study) wherein certain thinking processes used during reading and retelling are isolated and identified. In order to clarify procedure as applicable to this study, the theoretical basis, Irwin's overview of the comprehension process is provided below.

1. Microprocesses: understanding and selectively recalling idea units in individual sentences;

2. Integrative processes: understanding and inferring the relationships between individual clauses and sentences and inferring causation and sequence;

3. Macroproccesses: synthesizing and organizing ideas around more general summarizing concepts to develop overall an organizational pattern for the text;

4. Elaborative processes: making inference beyond the text; and

5. Metacognitive Processes: developing one's own strategies to effect comprehension and long-term recall of text, i.e., study strategies. 
Irwin (1986) provided a sample text, retelling and assessment of retelling to be used as a model for teachers when assessing retellings based on the above comprehension processes. The sample is set out below:

Sample Text:

The opponents of this tradition [judicial review] have been as loud as the tradition has been long. It is not surprising then that once again there are many who wish to restrict or perhaps even abolish judicial review. Especially in the 1980's, after nearly two decades of "liberal" Warren Court decisions, this tradition is being challenged by conservatives who oppose the Supreme Court's decisions on school prayer, busing, abortion, and rights of accused criminals. In fact, Congress is presently considering nearly 40 bills limiting the jurisdiction of the Federal Courts in such matters. (Irwin 1986:10)

Retelling:

It talked about how the courts can say whether a law is okay and some people don't like what the courts have done so the government might just get rid of the courts altogether. They are talking about passing forty laws to keep the courts from doing things about things like busing and school prayer like Sam talked about in his report last week. There was something about the King's clothes but I didn't understand it. I didn't really care because I thought it was a dumb article anyway. (Irwin 1986:10)

Assessment of retelling:

RECALL

"It talked about how the courts can say whether a law is OK and some people don't like what the courts have done so the government might just get rid of the courts altogether."

"They are talking about passing forty laws to keep the courts from doing things . . .

\section{PROCESS}

Macroprocesses (She has reduced the article to a kind of summary statement.)
Microprocesses

(She has remembered specific details that she thought were important.) 
" ... about things like

busing and school prayer

" . . . like Sam talked

about in his report last

week."

"There was something

about the King's clothes

but I didn't understand it.

I didn't really care because

it was a dumb article

anyway."
Integrative processes

(She has integrated two

sentences of the article.)

Elaborative processes

(She has linked this article

to something she heard

before.)

Metacognitive processes

(She was aware of what

she didn't understand and

decided not to do anything

about it.)

(Irwin 1986:11)

Because the scope of the second hypothesis was limited to the use of elaborations and supplementations, a simplified evaluation model, again based on Irwin's (1986) sample text, is shown below. It uses only the parts of the text and retelling containing supplementations and elaborations:

Sample text:

It talked about how the courts can say whether a law is okay and some people don't like what the courts have done so the government might just get rid of the courts altogether. They are talking about passing forty laws to keep the courts from doing things about things like busing and school prayer like Sam talked about in his report last week. (Irwin 1986:10)

\section{SUPPLEMENTATION:}

It talked about how the courts can say whether a law is OK and some people don't like what the courts have done so the government might just get rid of the courts altogether. They are talking about passing forty laws to keep the courts from doing things about things like busing and school prayer

\section{PROCESSES}

Subject has summarized and paraphrased text (macroprocessing); has integrated two sentences of the text (integrative processing); has remembered specific details and ommitted others (microprocessing). 
ELABORATION:

like Sam talked about in his report last week.
Student has made an association between text and something heard before; has substituted "like Sam talked about last week" for specific details not included and has assumed the reader's concurring memory of extra-textual knowledge (elaborative processing).

The procedure used in reviewing the written responses collected by the post-test II instrument was adapted from the procedure shown above. The coraters first examined the written responses to isolate elaborations and supplementations. After the responses were identified and categorized, they were counted and a level of use was assigned to each subject. The Irwin and Mitchell (1986) "Richness of Retellings Criteria" as adapted for the purposes of this study was used to assign a corresponding level of use (see Appendix D). The "Richness of Retellings Criteria" is also discussed in Chapter $V$ in the section regarding the non-statistical analysis of post-test II.

\section{Interrater Reliability}

The control group instructor and treatment group instructor served as co-raters of post-test II. Because of the subjective nature of the rating task, it was necessary for both raters to evaluate the responses of both groups. The raters evaluated the set of responses from their own group, then the exams were reviewed by the co-rater. In the case of ambiguous, irrelevant or otherwise questionable responses, the assessment criteria were further reviewed and discussed before a final determination was made. There were a 
total of 228 responses categorized. Of those, 21 were re-evaluated. The level of agreement between co-raters was approximately $92 \%$.

\section{Statistical Analysis of Data Collected}

T-tests. A t-test was applied to the scores of the pre-test to determine if there was any statistically significant difference in the reading ability of both groups. A t-test was also applied to the scores of post-test I to determine if there was any statistically significant increase between groups in recognition comprehension. A t-test was applied to the scores from pretest to post-test, within group only, to determine if there was any statistically significant difference in the two mean scores. A set of t-tests were applied to Post-test II to analyze the level of use of certain comprehension processes between groups.

Mann-Whitney U. Post-test II was also analyzed by a Mann-Whitney U test in order to rank the sums of the values for each group within the group on an ordinal scale. The means were then compared between groups.

Other. The data collected by the post-test II instrument was analyzed with a bar graph to provide a descriptive examination of the data. 


\section{CHAPTER IV}

\section{RESULTS}

This chapter reports the results of the tests used during the study. There were three test instruments: (1) The pre-test used to determine betweengroup comparability and (2) the two post-tests, one of which was designed to measure recognition comprehension, in this case, recall of factual detail, and the other was designed to measure certain comprehension processes, in this case, the inferencing skills of elaboration and supplementation.

\section{RESULTS OF THE PRETEST}

A one-tailed t-test for independent samples was used to determine any statistically significant difference in the reading ability of the two groups. A total raw score of 20 was possible for each subject. The range of scores for the control group was from 12 to 18 . The range of scores for the treatment group was from 10 to 20. The statistical values are shown in Table II.

TABLE II

RESULTS OF T-TEST COMPARING MEAN SCORES OF PRETEST

\begin{tabular}{|llll|}
\hline GROUP & NUMBER & MEAN & SD \\
\hline Control & 13 & 14.30 & 1.72 \\
Treatment & 14 & 15.07 & 2.76 \\
& & & df $=25$ \\
\hline pooled variances & $\mathrm{t}=.821$ & prob $=.419$ \\
\hline
\end{tabular}


Since the probability is greater than the level of significance (.05) the comparison of mean scores indicated there was no statistically significant difference in the reading ability between the two groups. Since the control and treatment groups were considered comparable in reading ability, no corresponding adjustment to post-test scores was required.

\section{RESULTS OF POST-TEST I}

Post-test I was designed to measure recognition comprehension, in this case, the subjects' ability to recall factual data. A total raw score of 15 was possible for each subject. The range of scores for the control group was from 7 to 12 . The range of scores for the treatment group was from 9 to 15 . To determine if any statistically significant difference existed between the two means, the one-tailed $\mathbf{t}$-test for two independent samples was calculated. The statistical values are shown in Table III.

TABLE III

RESULTS OF T-TEST COMPARING MEAN SCORES OF POST-TEST I

\begin{tabular}{|llll|}
\hline GROUP & NUMBER & MEAN & SD \\
\hline Control & 13 & 10.23 & \\
Treatment & 14 & 12.57 & 1.80 \\
& & & 1.80 \\
\hline Pooled variances & $\mathrm{t}=3.26$ & $\mathrm{df}=25$ & prob $=.003$ \\
\hline
\end{tabular}

Since the probability is less than the level of significance (.05), the comparison of mean scores indicated there was a statistically significant difference in the level of recognition comprehension. 


\section{RESULTS OF POST-TEST II}

\section{Non-Statistical Analysis}

Post-test II was designed to measure certain comprehension processes, specifically, the inferencing skills of elaboration and supplementation. Table, IV, The "Richness of Retellings Criteria" was used to rate the written responses collected from the post-test II by subject. Although this information is descriptive, it is included in this section in order to clarify Tables V, VI and VII (pp. $41-42$ ).

\section{TABLE IV}

\section{RICHNESS OF RETELINGS CRITERIA}

\begin{tabular}{ll}
\hline LEVEL & CRITERIA FOR ESTABLISHING LEVEL \\
\hline 5 & $\begin{array}{l}\text { Subject never relates text only as response. Subject uses a high } \\
\text { level of relevant elaborations and relevant supplementations; } \\
\text { subject provides a high level of appropriate supporting details; } \\
\text { subject uses no irrelevant elaborations and supplementations. }\end{array}$ \\
& $\begin{array}{l}\text { Subject infrequently relates text only as response. Subject uses } \\
\text { some relevant elaborations; subject uses a high level of relevant } \\
\text { supplementations; subject provides some appropriate supporting } \\
\text { details; subject uses little or no irrelevant elaborations and }\end{array}$ \\
& supplementations. \\
& Subject occasionally relates text only as response. Subject uses few \\
& relevant elaborations and some relevant supplementations; subject \\
provides few appropriate supporting details; subject uses some & irrelevant elaborations and supplementations. \\
& Subject frequently relates text only as response. Subject uses little \\
& or no relevant elaborations and few relevant supplementations; \\
subject provides little or no appropriate supporting details; subject \\
uses few irrelevant elaborations and supplementations. \\
Subject relates text only for most responses; subject uses little or no \\
relevant elaborations and/or supplementations; subject provides \\
little or no appropriate supporting detail; subject uses little or no \\
irrelevant elaborations and supplementations.
\end{tabular}


The Richness of Retellings measure in Table VII, above, was adapted from the Irwin and Mitchell 1983 "Richness of Retellings Criteria" assessment of comprehension model (see Appendix D). In this system the subjects are given credit for inferences found in their responses, and a level of use is assigned.

The written responses for each subject were evaluated. Each elaboration and supplementation identified was assigned a value. The value of an elaboration with supporting detail was 4 and without support was 3; the value of a supplementation with supporting detail was 2 and without support was 1 . Irrelevancies, which represent a misreading of text and contradict text content, were counted for frequency of occurrence only, and, as such, they had a 0 value rather than a negative value. For each subject, the sum of the values for each category was added. The highest value that any subject received was 39 . The lowest value any subject received was 0 . Then a level of use was assigned. The level of use assigned to each subject was based on an scale of 0 to 5 , with 5 being the highest level and 0 being the lowest level. (A subject who was rated at 0 had no elaborations or supplementations.) Table V, below, shows the sum of the values of elaborations and supplementations, the number of irrelevancies and the corresponding level of use assigned to each subject by group. 
TABLE V

VALUES EARNED BY SUBJECT

\begin{tabular}{|c|c|c|c|c|c|}
\hline $\begin{array}{l}\text { Control } \\
\text { Subject } \\
\end{array}$ & $\begin{array}{l}\text { Value of } \\
\text { Elabs. }\end{array}$ & $\begin{array}{l}\text { Value of } \\
\text { Suppls. }\end{array}$ & Sum & $\begin{array}{c}\text { Number of } \\
\text { Irr. }\end{array}$ & $\begin{array}{c}\begin{array}{c}\text { Level of } \\
\text { Use }\end{array} \\
\end{array}$ \\
\hline 1 & 4 & 10 & 14 & 1 & 2 \\
\hline 2 & 4 & 11 & 15 & 0 & 3 \\
\hline 3 & 0 & 11 & 11 & 1 & 2 \\
\hline 4 & 4 & 7 & 11 & 0 & 2 \\
\hline 5 & 12 & 10 & 22 & 0 & 4 \\
\hline 6 & 0 & 3 & 3 & 0 & 1 \\
\hline 7 & 0 & 11 & 11 & 0 & 2 \\
\hline 8 & 0 & 8 & 8 & 1 & 2 \\
\hline 9 & 8 & 13 & 21 & 1 & 3 \\
\hline 10 & 12 & 15 & 27 & 1 & 4 \\
\hline 11 & 0 & 7 & 7 & 1 & 2 \\
\hline 12 & 4 & 4 & 8 & 2 & 2 \\
\hline 13 & 0 & 0 & 0 & 0 & 0 \\
\hline Group Total & 48 & 110 & 158 & 8 & Avg: 2.30 \\
\hline $\begin{array}{c}\text { Treatment } \\
\text { Subject }\end{array}$ & $\begin{array}{l}\text { Value of } \\
\text { Elabs. }\end{array}$ & $\begin{array}{l}\text { Value of } \\
\text { Suppls. }\end{array}$ & Sum & $\begin{array}{l}\text { Number of } \\
\text { Irr. }\end{array}$ & $\begin{array}{l}\text { Level of } \\
\text { Use }\end{array}$ \\
\hline 1 & 0 & 10 & 10 & 0 & 2 \\
\hline 2 & 0 & 14 & 14 & 1 & 3 \\
\hline 3 & 4 & 13 & 17 & 1 & 3 \\
\hline 4 & 0 & 4 & 4 & 3 & 1 \\
\hline 5 & 0 & 11 & 11 & 2 & 2 \\
\hline 6 & 16 & 14 & 30 & 1 & 4 \\
\hline 7 & 14 & 16 & 30 & 1 & 4 \\
\hline 8 & 4 & 13 & 17 & 0 & 3 \\
\hline 9 & 16 & 10 & 26 & 1 & 4 \\
\hline 10 & 4 & 10 & 14 & 0 & 2 \\
\hline 11 & 0 & 15 & 15 & 1 & 3 \\
\hline 12 & 4 & 6 & 10 & 3 & 2 \\
\hline 13 & 24 & 15 & 39 & 0 & 5 \\
\hline 14 & 8 & 5 & 13 & 2 & 2 \\
\hline Group Total & 94 & 156 & 250 & 16 & Avg: 2.86 \\
\hline
\end{tabular}

The range of values and the corresponding level of use assigned are shown in Table VI below. 
TABLE VI

ASSIGNMENT OF LEVEL BASED ON VALUES

Range of Values Level of Use Assigned

$\begin{array}{ll}0 & 0 \\ 1-8 & 1 \\ 9-16 & 2 \\ 17-24 & 3 \\ 25-32 & 4 \\ 33-40 & 5\end{array}$

Table VII below summarizes the level of use by number of subjects by group.

\section{TABLE VII}

LEVEL OF USE BY NUMBER OF SUBJECTS IN EACH GROUP

CONTROL GROUP

No. of Subjects - Level of Use

$1-0$
$1-1$
$7-2$
$2-3$
$2-4$
$0-5$
TREATMENT GROUP

No. of Subjects - Level of Use

$0-0$

$1-1$

$5-2$

$4-3$

$4-4$

$1-5$

\section{Statistical Analyses of Post-test II}

After the evaluation procedure statistical tests were applied to the values.

Mann-Whitney U Test. The Richness of Retellings Criteria ranks the subjects' responses by category on an ordinal scale. A two-tailed MannWhitney $U$ test was applied to the data because it ranks the sums on an ordinal scale in order to establish the group mean before comparing the means between groups. The lowest level of probability that could provide significant 
results was .10 . In the case of elaborations, mean value of the treatment group was statistically significant at .10 . In the case of supplementations at the same probability level there was no statistically significant difference in the mean values.of the two groups. The statistical values are set out in the summary below.

\section{Elaborations (E scores):}

The value of the test statistic for the Mann-Whitney test is $S=148$ and the corresponding $z$-score has a value of -1.65 . This shows a statistical significant difference in the $\mathrm{E}$ scores between the two groups at a .10 level of significance.

\section{Supplementations (S scores):}

The value of the test statistic for the Mann-Whitney test is $S=163.5$ and the corresponding $\mathrm{z}$-score has a value of -.898 . This shows that there is no statistical significant difference in the $S$ scores between the two groups at a .10 level of significance.

T-Tests. T-tests were applied to the mean values of elaborations and supplementations. In the case of elaborations, the range of values for the control group was from 0 to 12 . The range of values for the treatment group was from 0 to 24 . To determine if any statistically significant difference existed between the two means, a one-tailed t-test for two independent samples was calculated. The statistical values are shown in Table VIII.

TABLE VIII

RESULTS OF T-TEST COMPARING MEAN VALUES FOR ELABORATION

\begin{tabular}{|llll|}
\hline GROUP & NUMBER & MEAN & SD \\
\hline Control & 13 & 3.69 & \\
Treatment & 14 & 6.71 & 4.46 \\
& & & 7.75 \\
\hline Pooled variances & $\mathrm{t}=1.21$ & $\mathrm{df}=25$ & prob $=.230$ \\
\hline
\end{tabular}


Since the probability is greater than the level of significance (.05), the comparison of mean values indicated there was no statistically significant difference in the use of elaboration between the two groups.

In the case of supplementations, the range of values for the control group was from 0 to 15 . The range of values for the treatment group was from 4 to 16 . To determine if any statistically significant difference existed between the two means, a one-tailed t-test for two independent samples was calculated. The statistical values are shown in Table IX.

TABLE IX

RESULTS OF I-TEST COMPARING MEAN VALUES FOR SUPPLEMENTATION

\begin{tabular}{|llll|}
\hline GROUP & NUMBER & MEAN & SD \\
\hline & & & \\
Control & 13 & 8.46 & 4.22 \\
Treatment & 14 & 11.14 & 3.88 \\
& & & prob $=.098$ \\
\hline Pooled variances & $\mathrm{t}=1.72$ & $\mathrm{df}=25$ &. \\
\hline
\end{tabular}

Since the probability is more than the level of significance (.05), the comparison of means indicated there was no statistically significant difference in the use of supplementation between the two groups. 
OTHER RESULTS

\section{Bar Graph}

The sum of the values for elaborations, supplementations and the frequency of irrelevancies between groups were ranked on an ordinal scale as shown in Figure 2, below.

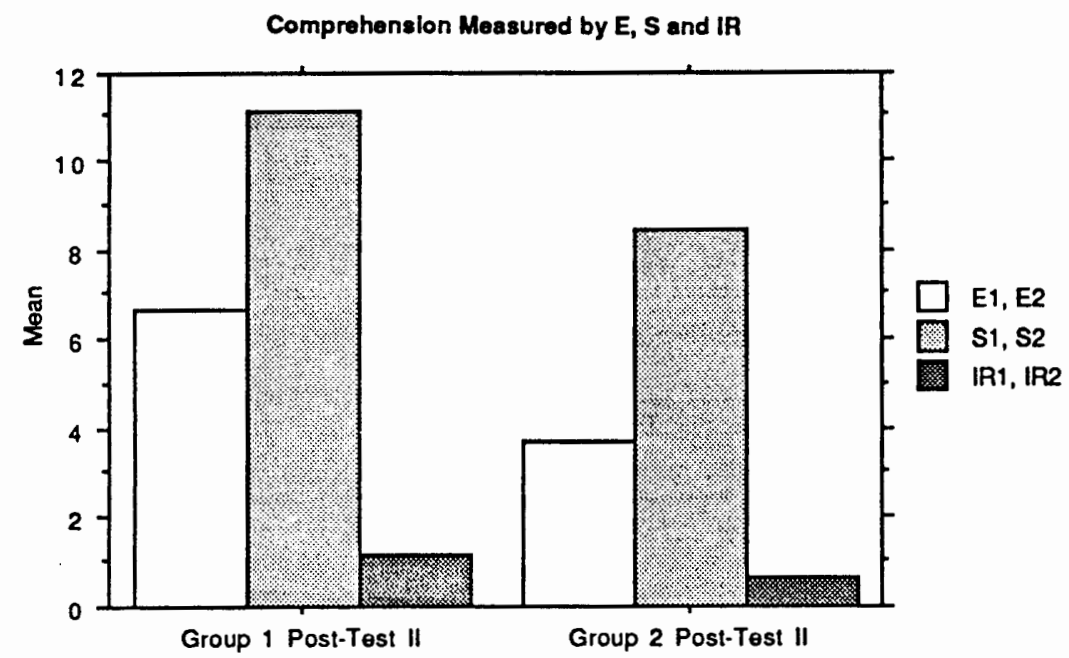

Figure 2. "Group 1" is the Treatment Group; "Group 2" is the Control Group; "E", "S", and "IR" stands for Elaborations, Supplementations, and Irrelevancies, respectively.

\section{Comparison of Mean Scores from Pretest to Post-test I}

A one-tailed $\mathbf{t}$-test was applied to the data which compared the scores within groups from pre-test to post-test I. Although a comparison of means from pretest to post-test I sits outside the hypotheses, the tests are useful to help clarify the results as discussed in Chapter V.

Because the pre-test had 20 points possible and post-test I had 15 points possible, the scores have been converted to rates in order to compare the means. The range of scores for the control group for the pre-test was from 12 to 18 , with a mean rate of .72 . For post-test I the range of scores was from 7 to 12 , with a mean rate of .68 . To determine if any statistically significant 
difference existed between the two means, a $\underline{t}$-test for two independent samples was calculated. The statistical values are in Table X.

TABLE X

RESULTS OF T-TEST COMPARING MEAN SCORES FROM PRETEST TO POST-TEST I

\begin{tabular}{|llll|}
\hline CONTROL GROUP & NUMBER & MEAN & SD \\
\hline Pretest & 13 & 0.72 & .09 \\
Post-test I & 13 & 0.68 & .13 \\
\hline Pooled variances & $\mathrm{t}=.79$ & $\mathrm{df}=24$ & prob $=.4367$ \\
\hline
\end{tabular}

Since the probability is greater than the level of significance (.05), a comparison of means indicated no statistically significant difference in recognition comprehension from pre-test to post-test I for the control group.

The range of scores for the treatment group for the pre-test was from 10 to 20 , with a mean rate of .75 . For post-test I the range of scores was from 11 to 15 , with a mean rate of .84 . To determine if any statistically significant difference existed between the two means, a t-test for two independent samples was calculated. The statistical values are shown in Table XI below.

TABLE XI

RESULTS OF T-TEST COMPARING MEAN SCORES FROM PRETEST TO POST-TEST I

\begin{tabular}{|llll|}
\hline TREAT. GROUP & NUMBER & MEAN & SD \\
\hline Pretest & & & \\
Post-test I & 14 & 0.75 & .14 \\
& 14 & 0.84 & .12 \\
\hline Pooled variances & $\mathrm{t}=-1.67$ & $\mathrm{df}=26$ & prob $=.1063$ \\
\hline
\end{tabular}

Since the probability is greater than the level of significance (.05), a comparison of means indicated no statistically significant difference in 
recognition comprehension from pre-test to post-test I for the treatment group.

A final t-test was applied to the data which compared the mean scores between groups of the frequency of irrelevant elaborations and supplementations (categorized as one item). Although a comparison of means of the number of irrelevant responses sits outside the hypotheses, the tests are useful to help clarify the results as discussed in Chapter V. The range of scores for the control group was from 0 to 2 . The range of scores for the treatment group was from 0 to 3 . A one-tailed t-test for two independent samples was calculated.to determine if any statistically significant difference existed between the two means, The statistical values are shown in Table XII.

TABLE XII

RESULTS OF T-TEST COMPARING MEAN SCORES FOR IRRELEVANCIES

\begin{tabular}{|llll|}
\hline GROUP & NUMBER & MEAN & \\
\hline Control & 13 & 0.62 & \\
Treatment & 14 & 1.14 & prob $=.13$ \\
\hline Pooled variances & $\mathrm{t}=1.58$ & $\mathrm{df}=25$ & \\
\hline
\end{tabular}

Since the probability is more than the level of significance (.05), the comparison of means indicated there was no statistically significant difference in the use of irrelevant elaborations and supplementations between the two groups. 


\section{SUMMARY}

\section{Summary of Non-Statistical Analysis of Post-test II}

By using an adaptation of the Irwin and Mitchell Richness of Retellings comprehension assessment model, the responses to post-test II were categorized, valued, and then a level of use was assigned to each subject ranging from 0 to 5 . The sum of the combined values of elaborations and supplementations was 158 for the control group and 250 for the treatment group. The average level of use was 2.30 for the control group and 2.86 for the treatment group.

\section{Summary of Statistical Analyses of Post-tests I and II}

At a probability level of .05 , the results of the $\underline{t}$-test showed a statistically significant increase in recognition comprehension between groups as measured by post-test I. At a probability level of .05 the results of the t-tests showed no statistically significant level of use between groups in the areas of elaboration and supplementation as measured by post-test II. However, when using the Mann-Whitney $U$ test to rank the data on an ordinal scale and then compare means between groups, significance at a probability level of .10 was found in the case of elaborations for the group receiving the treatment. However, in the case of supplementations, no corresponding level of significance was found.

In order to interpret these results further they must be discussed in light of the hypotheses as set out in Chapter I. They must also be discussed in light of certain moderating variables consequent to this study which were discussed in Chapter III in the sections describing the subjects, design and procedures of this study. 


\section{CHAPTER V}

\section{INTERPRETATION OF RESULTS}

This chapter interprets the various results of the measures used during this study. Due to the small sample sizes and lack of randomness, no conclusions should be drawn from the results that can be generalized beyond the scope of the study. However, the results did indicate certain trends. In the case of recognition comprehension, the treatment group did perform at a statistically significant level better than the control group. In the case of elaborations and supplementations, the treatment group did show a greater level of use than the control group, but it was not statistically significant.

\section{MODERATING VARIABLES}

In this studythe results cannot be interpreted solely on the basis of the effect of the independent variable upon the dependent variables. In Chapter III certain moderating variables such as ethnic diversity, previous language training of subjects and the differing levels of reading proficiency were mentioned. In order to control their effect on the dependent variables a pretest was given to measure reading ability before the study commenced.

\section{Instructional Variation}

Another important moderating variable discussed in Chapter III was the necessity of using different instructors for the control and the treatment groups. In an effort to limit the effect of this moderating variable on the 
dependent variables, the control group instructor and the treatment group met frequently before the study commenced to discuss the goals and purposes of the study; to collaborate on the selection of study text; to discuss the inclusion and content of other materials to be used in the study, such as the narrative outline and the mapping format, and to design the post-test instruments.

The class sessions during which the control group instructor explicated the subject text were taped in order for the researcher to identify differences, if any, in instructor style and presentation of materials that might be discussed as moderating variables. Although a reasonable effort was made by both instructors to approximate methods and procedures, as agreed upon and discussed, certain differences in instructor style and presentation of materials were evident from the audio tape. It cannot be known to what degree these differences (or moderating variables) might have affected the dependent variables; however, an adequate discussion of the results should include their identification and how they may have affected the results. In this way the purpose of the study, to examine the effectiveness of semantic mapping on reading comprehension, will be better understood not only within the context of the study, but in its effectiveness as an aid to comprehension in the second language reading classroom as well.

In the following paragraphs, each measure used in this study will first be discussed in review of its statistical analysis, and then in light of moderating variables which may be relevant to the results. 


\section{Discussion of the Results of the Pretest}

The results of the pre-test indicated no statistically significant difference in the mean rates between the control and treatment groups $(.72$ and .75 , respectively). The probability of this occurring was .419 . Because no statistically significant difference in mean scores was indicated, the groups were considered comparable in reading ability and no corresponding adjustment to post-test scores was required.

\section{Discussion of the results of Post-test I}

The statistical results supported the hypothesis that the subjects instructed in the use of semantic mapping would show a significant increase when tested for recognition comprehension. In reviewing the analysis of the tests, the mean rates of the control and treatment groups were .68 and .84 , respectively, with a difference of .16. The probability of this occurring was .003 . Thus, the null hypothesis was rejected and the alternate hypothesis was accepted.

Text Explication. The first moderating variable to be discussed concerns the difference in instructional methods employed by the instructors during the explication of the subject text. The subject text was divided into ten sections called "scenes." The recording of the control group instructor's class sessions revealed that even though the progression through the text was generally from beginning to end, there was considerable movement both forwards and backwards in the text as the explication progressed. For instance, at one point, while discussing an event from Scene $V$, the conversation moved back to a related incident in Scene II and then forward to Scene III before returning to Scene V. Although the text was discussed rom 
beginning to end, there was some digression and, consequently, the distribution of time spent on each scene varied.

On the other hand, the treatment, the construction of a semantic map, was designed to follow the cause and effect order of text content. Because the explication was based on causation (one event causes the next event which causes the next event), the progression though the text was systematic and methodical, and the time spent on each scene was more evenly distributed.

Study Questions. A second variable related to instructional methods has to do with the study questions provided by the textbook. (Recall that the subject text was selected from the course textbook in use by the control group at that time.) As was stated previously, both the control and treatment groups received a corresponding set of study questions to refer to while reading the text. Although neither instructor collected them from the subjects as homework, the control group instructor did refer to the study questions occasionally while discussion of the subject text was in progress, and, further, it had been the habit of the control group instructor to incorporate the study guide questions into text explication for reading required of the subject group previous to the study. The treatment group was advised only to review the study questions as part of the reading task, but the instructor did not refer to them during class sessions. Post-test I was not based on the study questions, but the control group may have relied more heavily on them for review purposes than did the treatment group because of their previous classroom experience.

Time. The third and last moderating variable relevant to the results of post-test I concerns the time spent by the subjects individually and in the classroom on the subject text. The control group was asked to read the entire 
story through before beginning classroom explication, and was given a weekend to pre-read the story. Discussion ensued over a two-class period (plus review). The treatment group was required to pre-read the story in three segments over a three-class period (plus review). Because the treatment group read the story in three segments with more in-class time spent in explication, they may have been able to read at a more comfortable rate and acquire more detail.

Comparision of Means from Pretest to Post-test I. A final discussion of the results of post-test I concludes with a comparison of the within groups means from the pre-test to post-test I. Although the comparison of scores from pre-test to post-test I within groups sits outside the hypotheses, these results are considered important to the interpretation of the results. The pre-test was a 20-point short answer quiz and the post-test I was a 15-point multiple choice and true/false quiz. The pre-test was given to assess comparability between groups and the post-test to assess the effect, if any, of the treatment on the dependent variable, recall of factual detail. In reviewing the analysis of the tests, the mean rates of the control group for pretest to post-test I were .72 and .68 , respectively, with a mean difference of .0338 . The probability of this occurring at a significance level of .05 was .436 . The mean rates for pretest to post-test I for the treatment group were .75 and .84 , respectively, with a difference of -.085 . The probability of this occurring was .1063 . As the data shows the control group performed less well on post-test I than on the pretest while the treatment group performed better.

As stated previously, the purpose for using each text was different, so no attempt was made to use equivalent texts for pre- and post-testing. The text used for the treatment and post-testing was much longer, more complex and 
more stylistic than the pretest. Even though the text used for post-testing was more difficult, the mean score of the treatment group improved. Although no strong conclusions can be drawn, the results suggest that using the treatment may have enabled the treatment group to improve their recall of factual data. This improvement may be explained in part by several factors. First, the time spent in the text differed for both groups, because the treatment obliged a slower progression through the text. Second, the application of the treatment caused an important difference in the text explication received by the two groups; that is, the treatment group received an explication that was more systematic and methodical, consistent with the cause and effect ordering of text content, than did the control group. Third, there was a difference in the way the groups preread the text. The control group was asked to preread the complete story and the treatment group was required only to preread the section of text that would be mapped during the following class session. Fourth, because the text was explicated and mapped as the reading progressed, it may be that the subjects formed a more ordered memorial representation of the subject text, thus reducing mixing up or crossing-over of factual detail.

\section{Discussion of the Results of Post-Test II}

Statistical Analyses. Post-test II was designed to measure certain thinking processes involved in forming written responses to questions about text content. For the purposes of this study, those processes were identified as the inferencing skills of (1) supplementation and (2) elaboration.

The t-tests analyzed the values of each for both groups. In the case of supplementations, the mean scores for the control and treatment groups were 11.14 and 8.46 , respectively, with a mean difference of 2.68 . The probability of 
this occurring was .0976 . In the case of elaborations, the results were similar. The mean scores for the control and treatment groups were 6.71 and 3.69 , respectively, with a mean difference of 3.02. The probability of this occurring was .2307 . Thus, in both categories the null hypothesis was retained and the alternative hypothesis was rejected.

The Mann-Whitney U test ranked the subjects' scores individually on an ordinal scale and then compared the means between groups. In the case of elaborations the treatment group showed a significantly higher level of use. However, there was no corresponding significant difference in the case of supplementations.

Although there was no statistically significant difference in the levels of use between groups, both types of inferencing occurred most frequently in the written responses of the treatment group. A close examination of the values on Table $V$ shows that the sum of the values of elaborations and supplementations made by the control and treatment groups was 158 and 250, respectively. In order for this to happen, the treatment group had to have done more actual writing in forming their responses than did the control group. This, in fact, was the case. When the exams were read, the quantity of writing produced by the members of the treatment group for each question was in most cases larger than the quantity of writing produced by the members of the control group. The value of elaborations for the control and treatment groups was 48 and 94, respectively, and the value of supplementations for the control and treatment groups was 110 and 156, respectively. In the case of elaborations, the treatment group had nearly twice the value of the control group (94 to 48). However, in the case of supplementations, the gap closed somewhat (110 to 156), so that the treatment 
group's lead dropped to a little more than a third again of the value of the control group.

\section{Non-Statistical Analysis of Post-test II}

In order to better understand the differences in the quantity and quality of writing between groups, a moderating variable related to writing ability should be discussed. Both groups had been placed at reading levels III and $\mathrm{IV}$ by college administration previous to the commencement of the study. Both groups had been placed at writing levels III and IV as well. No pretesting was done to establish writing comparability between groups because the post-test II instrument did not specify lengthy written responses.

Writing Ability. In review, elaborations are relevant comments that take the form of personal opinion or insight and/or a cultural bias of the subject. Supplementations are relevant comments that take the form of textual paraphrasing and/or rephrasing and summarization. In forming an elaboration, then, the subject will write about the text necessarily using more of his/her own phrasing. On the contrary, in forming a supplementation, the subject will rephrase and/or paraphrase and summarize text using his/her own phrasing to a lesser degree. Because the text to be considered in answering the test questions was supplied on the test instrument, the necessary vocabulary and phrasing to form a supplementation was available and the written responses could be considered text-dependent. Although an elaboration did not have to be lengthy or complex, a subject attempting to form an elaboration would have had to rely more heavily on existing mental stores for vocabulary and phrasing and the written responses would necessarily be more text-independent. 
Irrelevant Comments. Post-test II was also evaluated for irrelevant inferences and elaborations (as a combined category) made by the subjects. Irrelevancies indicate a misreading of the text and contradict with text content. They were not assigned a negative value but were considered pertinent to the study on the basis of frequency. The sum for the control and treatment groups was 8 and 16, respectively. The control group made half as many irrelevant (erroneous) comments as did the treatment group. In breaking down the sums of the irrelevancies into categories, it is interesting to note that the control group made only two irrelevant elaborations, while the treatment group subjects made nine irrelevant elaborations. It may also be assumed that misreading of text content indicates lack of a reading ability at the level of word recognition. Because the treatment group may have possessed greater writing ability, even though, in this case, they misread the text, they were able to form a greater number of text-independent responses.

\section{SUMMARY}

The discussion of the results in this chapter was intended to bring to light certain moderating variables and limitations of the study which may have affected the results. However, the discussion was not intended to suggest that the independent variable, semantic mapping, did not affect the dependent variable. The treatment group did score significantly higher than the control group on Post-test I. Even though the results of Post-test II were not statistically significant (with the exception of the Mann-Whitney means comparison of elaboration scores), the quantity of writing and the type of responses produced by the treatment group compared to those of the control showed considerably greater use. The test instrument questions did not 
specify that lengthy written responses were required. The treatment group formed nearly twice the number of elaborations about text content than the control group (48 to 94). In the case of supplementations, the treatment group formed almost a half again as many responses than the control group (110 to 156). This suggests that the treatment may aid the ability to make inferences about text content. 


\section{CHAPTER VI}

\section{SUMMARY, CONCLUSIONS, AND RECOMMENDATIONS}

\section{SUMMARY}

Much research has been done in the last two decades regarding the nature of the reading act. Previous to this time, reading was generally understood as primarily a perceptual, decoding task relying heavily on the linguistic skills of the reader. Beginning with Goodman's studies dating back to the late 1960 's, reading became understood as a process, a complex of cognitive and perceptual skills held by the reader that interacted simultaneously during reading. Goodman identified those cognitive skills as sampling, predicting, testing and confirming (or top-down). Those skills were activated by certain perceptual skills -- graphophonic, syntactic and semantic (or bottom-up). This interactive process became known as "psycholinguistic." Reading theorists began actively researching the psychological aspect of reading to acquire greater insight into its role in the reading process. As research continued, a component of psycholinguistic reading theory having to do with the activity of an individual's schema in the reading process garnered considerable attention. Schema theory, in this case, refers to the background knowledge a reader brings to the reading task and how that knowledge (or lack of it) is relevant to reading comprehension. During the late 1970's and early 1980's Rumelhart, among others, was investigating this relationship. Rumelhart viewed a reader's schema, as essential to achieving 
comprehension, and, further, he gave schema a functional specification which greatly increased its relevance to reading comprehension. In his view an individual's schema was not a mere passive recipient of incoming data, but it was an active, knowledge-generating structure which governed the reader's interpretation of the incoming data. Thus, the relationship between the reader's schema, text content and comprehension was established.

About the same time other reading researchers were investigating the relationship between schema, text structure and reading comprehension. In the 1980's Goetz and Armbruster concluded that not only does a reader better comprehend a text that is well-structured, but if a text lacks structure, the reader will form a structured memorial representation by default based on his/her existent schematic stores. The significance of their findings was that readers possess formal, rhetorical schemata which they will apply to a text, if need be, in order to comprehend the text.

In reaching their conclusion, Goetz and Armbruster relied heavily on the research that was being done in the late 1970's by Meyer and Stein and Glenn. These researchers were investigating the relationship between text structure in both expository prose and fiction and attempting to clarify its role in both the writing and reading processes. They first isolated and identified certain text structures and established several categories including cause and effect, time-sequence, comparison and contrast, description and others. In the case of fiction, certain components of a well-developed story were isolated and identified. These parts and their relationship to each other formed what came to be called the grammar of a story or "story grammar" (sometimes also referred to as story schema) A very brief story grammar could consist of a setting, plot, and resolution. 
While this early research was mainly being done in first language reading classrooms, second language researchers were keeping a close eye on the progress made. Eskey (1986) cited the work of Stanovich (1980), who compared the reading strategies of good and poor readers. His study showed that both good and poor readers develop compensatory strategies in order to achieve comprehension. His notion of "compensatory processing" (1980:63) assumes "that a deficit in any knowledge source results in a heavier reliance on other knowledge sources, regardless of their level in the processing hierarchy" (1980: 63). Further, he says that poor readers who have a deficit in word analysis skills tend to rely heavily on contextual factors, but that as their reading ability improves they are just as likely to use the conceptuallybased, higher level processes as good readers. Eskey (1986) concludes that "developing readers must therefore work at perfecting both their bottom-up recognition skills and their top-down interpretation strategies" (p. 95). His concern is that second language teachers develop strategies that will enhance the interactive reading process based upon a realistic model of a second language reader; that is, strategies that will improve bottom-up language decoding skills, and, at the same time integrate top-down interpretative skills.

In the mid-1980's Carrell and Carrell and Eisterhold, working first in writing, conducted studies to assess the importance of teaching formal, rhetorical structure in the second language writing classroom. They found that instruction in text structure or organizational patterns did benefit the learner in creating a more coherent, cohesive writing product. They later investigated the importance of teaching text structure in the reading classroom. Studies conducted between the mid- to late 1980's showed that second language learners could benefit from instruction in text structure, 
both in expository and narrative prose. Further, those studies indicated that it may be even more important for second language learners to have instruction in text structure for two reasons: (1) because of their lower reading proficiency, important, text-embedded linguistic cues are often missed, and (2) because reader's come to the text with pre-existing textual schemata related to text structure, and because certain text structures are culturally based, second language learners may hold conflicting textual schemata.

Once it can be established that instruction in text structure can benefit the second language reader, the question of "How?" remains. In a 1989 study Carrell, Pharis and Liberto found support for the use of semantic mapping. Typically, a map is constructed to follow the predominant pattern of the text. In this way the students are taught to see the relationship between content schema (or story events) and textual schema (organizational structure).

Underlying the Carrell, Pharis and Liberto (1989) study was an assumption that teaching text structure would increase reading comprehension in a between-group comparison. They found evidence to support that assumption. "The group trained on story maps recalled significantly more of both narrative and expository texts than a control group" . . (Carrell, Pharis and Liberto, 1989: 733). Since that time, however, little research has been done in this area.

This study was conducted to investigate that same assumption. It was hypothesized that using the semantic mapping technique would result in a significant increase in comprehension between groups. In addition, comprehension was further categorized: (1) recognition comprehension as the ability to recall factual detail from text content, and (2) comprehension as evidenced by the use of certain inferencing skills, namely, supplementation 
and elaboration in the subjects'written responses to questions. The study consisted of two separate groups totalling 27 subjects. The control group consisted of thirteen subjects. The treatment group consisted of fourteen subjects. Both groups read the same story. At the end of the reading task both groups were received the same two post-tests in order to test the hypotheses.

The first hypothesis stated that the group receiving the treatment would score significantly higher in recognition comprehension. A t-test was run on the data collected. At a significance level of .05 , the hypothesis was supported. The second hypothesis stated that the group receiving the treatment would show significantly greater use of certain inferencing skills, namely, supplementation and elaboration. Two statistical analyses were run on the data collected, t-tests and a Mann-Whitney $U$. The t-tests showed that at a significance level of .05 there was no statistically significant difference between the groups. However, using the Mann-Whitney $U$ at a significance level of .10 , the treatment group showed a statistically significant difference in the use of elaborations (but not in supplementations). After considering the results the second hypothesis was rejected.

\section{CONCLUSIONS}

\section{Limitations of the Study}

Because of the lack of randomness and small group sizes, the results cannot be generalized to a wider population. Thus, the findings of this study cannot be presented conclusively. In addition, there were moderating variables operational during the study for which the researcher either was either not able to control or did not attempt to control that may have affected the results: 
1. The use of two instructors allowed variations in instructor style and presentation.

2. Time is a factor that may have confounded the results in two ways:

a. The time between prereading of the study text and taking post-test I differed for both groups. The control group was asked to preread the entire text in advance of classroom explication; the treatment group was directed to pre-read only those sections which would be covered in the next class session. Because of this, there was a longer period of time between prereading and taking post-test I for the control group than for the treatment group.

b. The time spent in text explication differed between the two groups. The control group received two class sessions of explication; the treatment group received three sessions of explication.

3. The supplements to the study text, i.e., the study questions and the glossary and informal speech sections should not have been included in the materials used in this study. The use or lack of use of them may have affected the results.

4. Providing an outline to the control group was an unnecessary inclusion in study materials. It cannot be assumed that in a typical ENR reading classroom, an outline would have been provided.

5. The choice of study text did not clearly show cause and effect as the dominant organizational pattern. 
6. The use of focus questions on the post-test II instrument may have confounded the results with regard to the subjects' level of use of supplementations and elaborations. Because the test instrument provided the text from which the subject's were asked to form their responses, the subjects may have used a higher level of supplementations than elaborations. If retellings from memory of a certain scene (or scenes) had been required, it may be that the subjects would have used a greater number of elaborations.

7. The level of writing ability may have differed between groups.

\section{Recommendations for Further Research}

The interpretation of the results of the study in Chapter $\mathrm{V}$ as well as the foregoing the limitations shows that more research in this area is necessary to determine if further support for the instruction of text structure using the semantic mapping technique can be found. For this reason the following recommendations are made:

1. Future research should be designed to be used with a larger sampling and should include random sampling.

2. One instructor should work with both groups. In this way, moderating variables related to instructional variation and the difference in time spent in classroom explication can be eliminated or reduced. Also, the time difference between prereading and post-testing for both groups can be managed so as to minimize the difference. 
3. The study text used should be a clear example of the organizational pattern to be explicated in classroom discussion and represented by the semantic mapping procedure.

4. Eliminate any study materials related to the text which are not essential to the study. This would include any other form of text organizer, such as a narrative outline, and any materials designed by the publisher to accompany the text such as study guide questions, a glossary, or any other word helps.

5. The study materials should be revised to use a post-reading data collection instrument which can be used to evaluate retellings. The purpose of this instrument would be to collect data that is not predisposed toward supplemental responses.

6. Due consideration should be given to administering a writing pretest to determine writing ability of both groups. This step will be essential if the study is designed to use retellings rather than short written responses.

\section{IMPLICATIONS FOR TEACHING}

Because of the range of the limitations of this study, the results cannot be stated conclusively; however, they do indicate certain trends. They indicate that it is likely that instruction in text structure using the semantic mapping technique will help the second language reader recall factual detail from text content. It also indicates that it is likely that the semantic mapping technique will help the reader make extra-textual associations, that is to form associations between text content and their own personal world knowledge. 
If the second language instructor is looking for a strategy to explicate a difficult or complex text, this strategy may prove beneficial because the approach required by this technique provides the reader with a coherent, holistic representation of the text based upon a methodical, but logical progression through the text. Because the technique is so methodical, it may be that (1) more factual detail is discussed, and (2) the student is better able to retain that detail. That may be because the detail is discussed within its relationship to the structure of the text and is thus categorized more efficiently making the detail easier to bring into recall.

If the instructor is seeking to improve other comprehension skills related to the student's inferencing skills, then semantic mapping may be an appropriate technique to use. It may be that the systematic approach to the text obliged by the technique (as used in this study) allowed the treatment subjects to form more inferences both inter-sententially (supplementations) and extra-textually (elaborations). It should be stated at this point that if an instructor is seeking to produce elaborating inferences, the idea of a "wrong answer" should be abandoned. The critical point here is that elaborations are responses that show what associations the reader is making between the text content and what he/she already knows. An elaboration may be irrelevant in that it contradicts or conflicts with text content, but it is not wrong.

Although the results of this study indicated that second language students can benefit from instruction in text structure and that semantic mapping is an appropriate technique to use, the goal of the instructor should first be determined when considering the use of semantic mapping in the second language classroom. 


\section{REFERENCES}

Anderson, Richard C. and Pearson, David P., (1988). A schema-theoretic view of basic processes in reading comprehension. In Carrell, Patricia, Devine, Joanne, and Eskey, David (Eds.), Interactive approaches to second language reading. 37-55. Cambridge, NY: Cambridge University Press.

Arthur, Robert. (1988). The Midnight Visitor. In Baudoin, Margaret E., Bober, Ellen S., Clarke, Mark A., Dobson, Barbara K., and Silberstein, Sandra, (Eds.), Reader's choice. 2nd ed. Ann Arbor, MI: Univ. of Michigan Press.

Carrell, P.L. (1984). Text as interaction: some implications of text analysis and reading research for ESL composition. Paper presented at the annual meeting of the Teachers of English to Speakers of Other Languages.

Carrell, P. L. (1985). Facilitating ESL reading by teaching text structure. TESOL Quarterly. 19(4), 727-747.

Carrell, P.L., \& Eisterhold, J.C. (1987). Schema theory and ESL reading pedagogy. In M.H. Long \& J.C. Richards, (Eds.), Methodology in TESOL: a book of readings. 218-232. New York: Harper \& Row.

Carrell, Patricia L. Pharis, Becky G., and Liberto, Joseph. Metacognitive Strategy Training for ESL Reading. TESOL Quarterly. 23(4). 647-678.

Clarke, Mark A., and Silberstein, Sandra (1987). Toward a Realization of Psycholinguistic Principles in the ESL Reading Class. In M.H. Long \& J.C. Richards, (Eds.), Methodology in TESOL: a book of readings. 233247. New York: Harper \& Row.

Devine, Joanne. (1988). The relationship between general language competence and second language reading proficiency: implications for teaching. In Carrell, Patricia, Devine, Joanne, and Eskey, David (Eds.), Interactive approaches to second language reading. 260-277. Cambridge, NY: Cambridge University Press.

Devine, Thomas G. (1986). Teaching reading comprehension. Newton, MA: Allyn and Bacon, Inc. 
Eskey, David E. (1986). Theoretical foundations. In Dubin, F., Eskey, D.E., and Grabe, W. (Eds.), Teaching second language reading for academic purposes. 3-23. Reading, Mass.: Addison Wesley Publishing Company, Inc.

Eskey, David E. (1988). Holding in the bottom: an interactive approach to the language problems of second language readers. InCarrell, P., Devine, J. and Eskey, D. (Eds.), Interactive approaches to second language reading. 93-100. New York: Cambridge Univ. Press.

Gerhard, Christian. (1975). Making sense: reading comprehension improved through categorizing. Delaware, N.J.: International Reading Association:

Goetz, Ernest T. and Armbruster, Bonnie B. (1980). Psychological correlates of text structure. In Spiro, Rand J., Bruce, Bertram C., and Brewer, William F., (Eds.), Theoretical Issues in reading comprehension: perspectives from cognitive psychology, linguistics, artificial intelligence, and education. 201-220. Hillsdale, NJ: Lawrence Erlbaum Associates, Inc.

Goodman, K.S. (1967). Reading: A psycholinguistic guessing game. Journal of the Reading Specialist. 5, 126-135.

Goodman, K. S. (1988). The reading process. In Carrell, P., Devine, J., and Eskey, D., (Eds.), Interactive approaches to second language reading. 11-21. New York: Cambridge Univ. Press.

Grabe, W. (1986) The transition from theory to practice. In Dubin, F., Eskey, D.E., and Grabe, W., (Eds.), Teaching second language reading for academic purposes. 25-48. Reading, Mass: Addison Wesley Publishing Company, Inc.

Guthrie, John T. (1981). Comprehension and teaching: research reviews. Newark, DE: International Reading Association.

Heimlich, Joan E. and Pittelman, Susan D. (1986). Semantic mapping: classroom applications. Newark, DE: International Reading Association.

Irwin, Judith Westphal (1991). Teaching reading comprehension processes, 2nd ed. Englewood Cliffs, NJ: Prentice Hall.

Irwin, Judith Westphal (1986). Teaching reading comprehension processes. Englewood Cliffs, NJ: Prentice Hall.

Meyer, Bonnie J.F. and Freedle, Roy O. (1984). Effects of discourse types on recall. American Educational Research Journal. 21(1), 121-143. 
Meyer, Bonnie J.F. (1977). The structure of prose: Effects on learning and memory and implications for educational practice. In Richard C. Anderson, Rand J. Spiro, and William E. Molntague (Eds.), Schooling and the acquisition of knowledge. $179-200$. Hillsdale, NJ: Lawrence Erlbaum Associates.

Meyer, Bonnie J.F., David M. Brandt, and George J. Bluth (1980). Use of toplevel structure in text: key for reading comprehension of ninth grade students. Reading Research Quarterly. 16:(1), 72-103.

Meyer, Bonnie J.F., Maryilyn J. Haring, David M. Brandt, and Carol H. Walker. 1980. Comprehension of stories and expository text. Poetics. $9(1-3)$, 203-211.

Porter, Katherine Ann. (1984). Rope. In Mullen, Jean, (Ed), Outsiders: American short stories for students of ESL. Englewood Cliffs, NJ: Prentice Hall.

Reutzel, D. Ray. (1985). Story maps improve comprehension. The Reading Teacher. $\underline{38}(4), 400-404$.

Rumelhart D. E. (1980). Schemata: The building blocks of cognition. In Spiro, Rand J., Bruce, Bertram C., and Brewer, William F. (Eds.), Theoretical Issues in reading comprehension: perspectives from cognitive psychology, linguistics, artificial intelligence, and education. 33-58. Hillsdale, NJ: Lawrence Erlbaum Associates, Inc.

Stanovich, Keith E. (1980). Toward an interactive-compensatory model of individual differences in the development of reading fluency. Reading Research Quarterly. 16(1), 32-71.

Stein, N.L., and Glenn, C.G. (1978). An analysis of story comprehension in elementary school children. In R. Freedle (Ed.), Discourse processing: multidisciplinary perspectives. $53-120$. Hillsdale, NJ: Lawrence Erlbaum Associates, Inc.

Tonjes, Marian J., and Zintz, Miles V. (1981). Teaching reading thinking study skills in content classrooms, 3rd ed. Dubuque, IA: Wm. C. Brown, Inc. 
APPENDIX A

PRETEST TEXT

PRETEST INSTRUMENT 
Mystery stories are written to involve readers in solving a problem. The problem is presented early in the passage and the tension grows gradually until it is solved.

In this story, a man named Ausable will certainly die unless he can outsmart his enemy. Read the story carefully. You should be able to solve the problem before the end of the story.

\section{THE MIDNIGHT VISITOR}

\section{Robert Arthur}

Ausable did not fit the description of any secret agent Fowler had ever read about. Following him down the musty corridor of the gloomy French hotel where Ausable had a room, Fowler felt disappointed. It was a small room, on the sixth and top floor, and scarcely a setting for a romantic figure.

Ausable was, for one thing, fat. Very fat. And then there was his accent. Though he spoke French and German passably, he had never altogether lost the New England accent he had brought to Paris from Boston twenty years ago.

"You are disappointed," Ausable said wheezily over his shoulder. "You were told that I was a secret agent, a spy, dealing in espionage and danger. You wished to meet me because you are a writer, young and romantic. You envisioned mysterious figures in the night, the crack of pistols, drugs in the wine."

"Instead you have spent a dull evening in a French music hall with a sloppy fat man who, instead of having messages slipped into his hand by darkeyed beauties, gets only an ordinary telephone call making an appointment in his room. You have been bored!" The fat man chuckled to himself as he unlocked the door of his room and stood aside to let his frustrated guest enter.

"You are disillusioned," Ausable told him. "But take cheer, my young friend. Presently you will see a paper, a quite important paper for which several men and women have risked their lives, come to me in the next-to-last step of its journey into official hands. Some day soon that paper may well affect the course of history. In that thought is drama, is there not?" As he spoke, Ausable closed the door behind him. Then he switched on the light.

And as the light came on, Fowler had his first authentic thrill of the day. For halfway across the room, a small automatic pistol in his hand, stood a man.

Ausable blinked a few times.

"Max," he wheezed, "you gave me quite a start. I thought you were in Berlin. What are you doing in my room?"

Max was slender, not tall, and with a face that suggested the look of a fox. Except for the gun, he did not look very dangerous. 


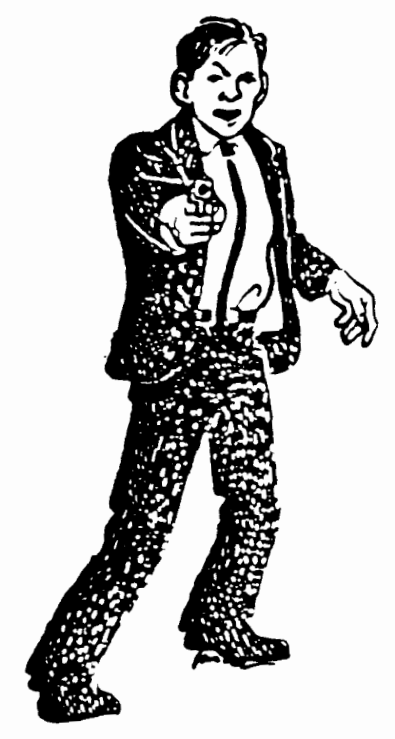

"The report," he murmured. "The report that is being brought to you tonight concerning some new missiles. I thought I would take it from you. It will be safer in my hands than in yours."

Ausable moved to an armchair and sat down heavily. "I'm going to raise the devil with the management this time; I am angry," he said grimly. "This is the second time in a month that somebody has gotten into my room off that confounded balcony!" Fowler's eyes went to the single window of the room. It was an ordinary window, against which now the night was pressing blackly.

"Balcony?" Max asked curiously. "No, I had a passkey. I did not know about the balcony. It might have saved me some trouble had I known about it."

"It's not my balcony," explained Ausable angrily. "It belongs to the next apartment." He glanced explanatorily at Fowler. "You see," he said, "this room used to be part of a large unit, and the next room-through that door there-used to be the living room. It had the balcony, which extends under my window now. You can get onto it from the empty room next door, and somebody did, last month. The management promised to block it off. But they haven't."

Max glanced at Fowler, who was standing stiffly a few feet from Ausable, and waved the gun with a commanding gesture. "Please sit down," he said. "We have a wait of half an hour, I think."

"Thirty-one minutes," Ausable said moodily. "The appointment was for twelve-thirty. I wish I knew how you learned about the report, Max."

The little spy smiled evilly. "And we wish we knew how your people got the report. But, no harm has been done. I will get it back tonight. What is that? Who is at the door?"

Fowler jumped at the sudden knocking at the door. Ausable just smiled, "That will be the police," he said. "I thought that such an important paper as the one we are waiting for should have a little extra protection. I told them to check on me to make sure everything was all right." 


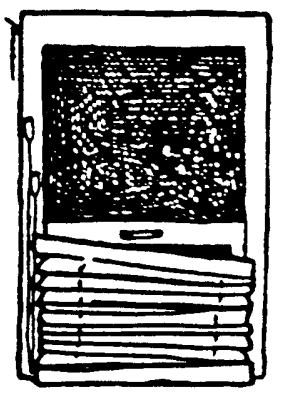
repeated.

Max bit his lip nervously. The knocking was

"What will you do now, Max?" Ausable asked. "If I do not answer the door, they will enter anyway. The door is unlocked. And they will not hesitate to shoot."

Max's face was black with anger as he backed swiftly toward the window; with his hand behind him, he opened the window and put his leg out into the night. "Send them away!" he warned. "I will wait on the balcony. Send them away or I'll shoot and take my chances!"

The knocking at the door became louder and a voice was raised. "Mr. Ausable! Mr. Ausable!"

Keeping his body twisted so that his gun still covered the fat man and his guest, the man at the window grasped the frame with his free hand to support himself as he rested his weight on one thigh. Then he swung his other leg up and over the window sill.

The doorknob turned. Swiftly Max pushed with his left had to free himself and drop to the balcony. And then as he dropped, he screamed once shrilly.

The door opened and a waiter stood there with a tray, a bottle and two glasses. "Here is the drink you ordered, sir." He set the tray on the table, deftly uncorked the bottle, and left the room.

White faced and shaking, Fowler stared after him. "But . . . but . . . what about . . . the police?" he stammered.

"There never were any police." Ausable sighed. "Only Henry, whom I was expecting."

"But what about the man on the balcony . . .?" Fowler began.

"No," said Ausable, "he won't return."

Adapted from "The Midnight Visitor" from Mystery and More Mystery, by Robert Arthur. (New York: Random House, 1939). 
Answer the following questions about the reading "The Midnight Visitor." Each answer is worth two points.

1. Who was Ausable? Describe him.

2. Where did he come from? How long ago did he leave?

3. Who was Fowler? (What was his job, or what did he do?)

4. How many languages could Ausable speak? What were they?

5. What is the setting for the story? (Where did it take place?)

6. Who was Max?

7. What did Max want?

8. Who came to the door?

9. What happened to Max?

10. What kind of story is the Midnight Visitor? 
APPENDIX B

POST-TEST TEXT

STUDY QUESTIONS

POST-TEST INSTRUMENTS I AND II 
XI

\section{Rope}

Story Setting: A plain, country farmhouse typical of many rural homes in America a few years ago (and some even now), where there are no close neighbors and often none of the amenities or conveniences such as electricity and running water.

In the Story: A young married couple have a quarrel over n very trivial matter, as lovers often do. What happens, however, is of less importance than the way it is told. There is no direct dialogue; yet the story consists almost entirely of conversation between the husband and wife, expressed indirectly but in accurate detail.

A Special Note Conceming this Story: The best stories ask something of the reader. They invite one to think, to figure out subtle implications, and to use one's imagination. In responding to the author's challenge, the reader is, in a sense, bringing the story to life-helping to create it anew. It is a very exciting and specinl kind of reading.

"Rope" has few long or complicated words, but it can be difficult for a nonnative speaker because it is loaded with many of the colloquial expressions and clichés that abound in American speech. These expressions have little or no definable meaning and therefore are labeled here as "indefinite" (indef). They are worthless additions to most writing except in portraying ordinary conversation, where there is a very human tendency to use them to avoid unpleasant confrontations.

In a story like this, then, the careful reader will want to watch closely in order to be aware of what is really going on. You will often find the speakers' meaning obscure, their words exaggerated, and their reasoning foggy and illogical-but listen to their tone!

Note also that although the author's text has been left in its exact, original form, two variations have been made in the format in order to aid you in your reading and in your study activities. First, certain passages are in italics: these passages are the only parts of the story that are not conversation. Second, the story has been arbitrarily divided into ten sections, or scenes, to make it easier to find the answers to the study questions, and then to prepare the way for the Special Group Project to follow. 
On the third day after they moved to the country he came walking back from the village carrying a basket of groceries and a twenty-four-yard coil of rope. She came out to meet him, uiping her hands on her green smock. Her hair was tumbled, her nose scarlet with sunburn; he told her that already she looked like a born country woman. His gray flannel shirt stuck to him, his heavy shoes were dusty. She assured him he looked like a rural character in a play.

Had he brought the coffee? She had been waiting all day long for coffee. They had forgot it when they ordered at the store the first day.

Gosh, no, he hadn't. Lord, now he'd have to go back. Yes, he would if it killed him. He thought, though, he had everything else. She reminded him it was only because he 10 didn't drink coffee himself. If he did he would remember it quick enough. Suppose they ran out of cigarettes? Then she saw the rope. What was that for? Well, he thought it might do to hang clothes on, or something. Naturally she asked him if he thought they were going to run a laundry? They already had a fifty-foot line hanging right before his eyes. Why, hadn't he noticed it, really? It was a blot on the landscape to her.

\section{II}

He thought there were a lot of things a rope might come in handy for. She wanted to know what, for instance. He thought for a few seconds, but nothing occurred. They could wait and see, couldn't they? You need all sorts of strange odds and ends around a place in the country. She said, yes, that was so; but she thought just at that time, when every penny counted, it seemed funny to buy more rope. That was all. She hadn't meant anything else.

20 She hadn't just seen, not at first, why he felt it was necessary.

\section{GLOSSARY}

2 coil of rope: rope that has been wound in loose circles, for easier hanoling.

3 smock: a loose garment worn over clothes to protect them.

3 tumbled: mussed up.

4 a born country woman: one who has always lived on a farm.

13 run a loundry: manage a business based on washing people's clothes.

\section{INFORMAL SPEECH}

8 Gosh... Lord: mild forms of swearing.

8 would if th killed him: exaggeration to show he really meant what he said.

11 ran out of: used up the supply.

$11 \mathrm{H} \mathrm{might} \mathrm{do:} \mathrm{might} \mathrm{serve} \mathrm{the} \mathrm{need}$ of something (usually said in a doubtful, unenthusiastic way).

14 blot on the landscape (cliche): an ugly object that spoils the scenery. an "eyesore."

15 might come in handy for: might have an unexpected usefulness.

16 wait and see (indef): perhaps later (a way of stalling or avoiding the issue).

17 odds and ends: assorted things with no particular use or relation to other things.

18 when every penny counted (cliche): when money was very scarce.

\section{STANDARD VOCABULARY}

3 scarlet: bright red.

5 esseured: told him very confidently.

9 reminded: caused (him) to remember. 


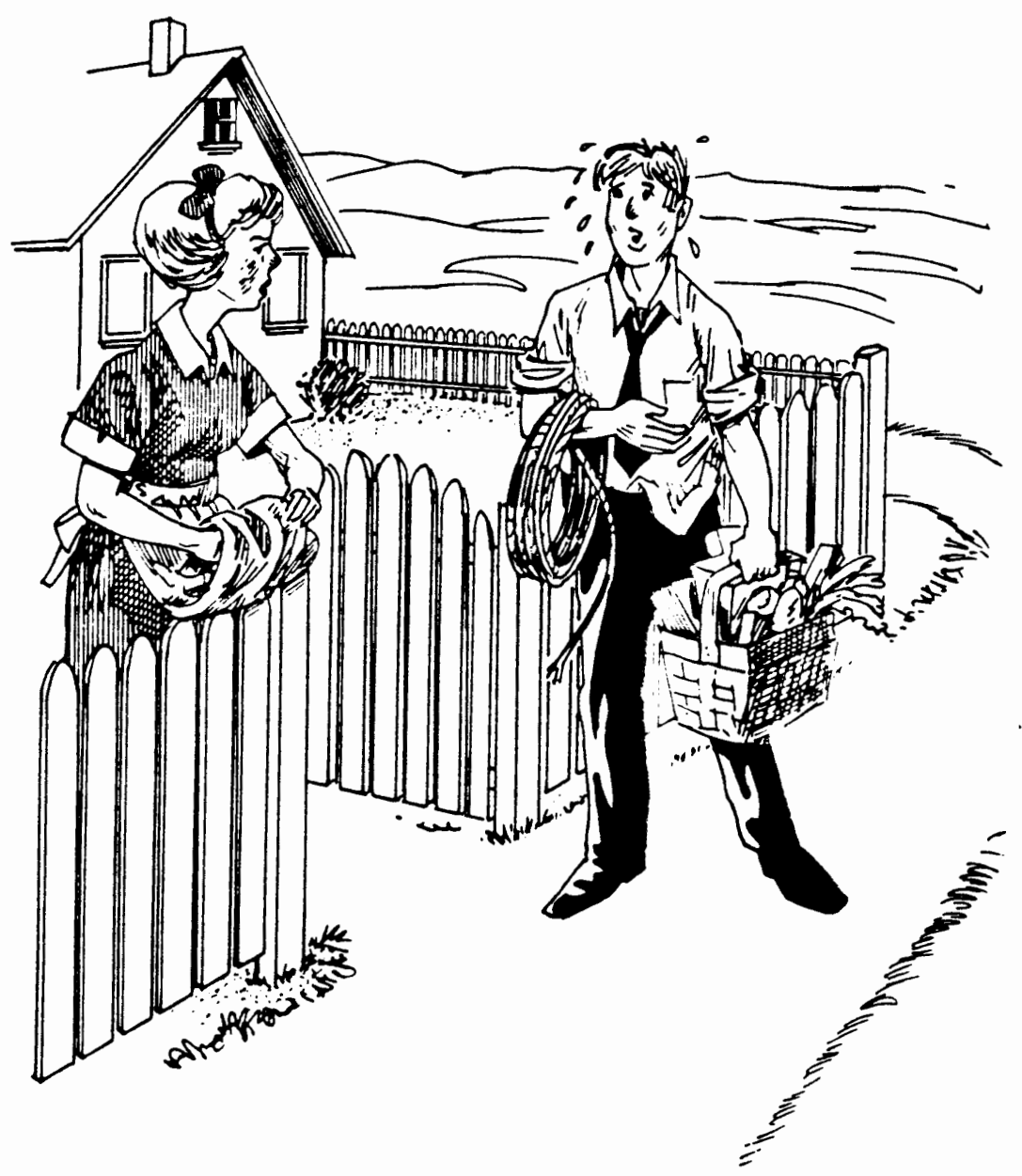

Well, thunder, he had bought it because he wanted to, and that was all there was to it. She thought that was reason enough, and couldn't understand why he hadn't said so, at first. Undoubtedly it would be useful, twenty-four yards of rope, there were hundreds of

21 Well, thunder: an expression of annoyance.

21 ell there was to It (stress word is to): usually has a double meaning: 10 indicate the matter is simple-no hidden meanings-but also to hint very strongly that one doesn't want to talk about it any more. 
things, she couldn't think of any at the moment, but it would come in. Of course. As he had said, things always did in the country.

But she was a little disappointed about the coffee, and oh, look, look, look at the eggs! Oh, my, they're all running! What had he put on top of them? Hadn't he known eggs mustn't be squeezed? Squeezed, who had squeezed them, he wanted to know. What a silly thing to say. He had simply brought them along in the basket with the other things. If they

30 got broke it was the grocer's fault. He should know better than to put heavy things on top of eggs.

\section{III}

She believed it was the rope. That was the heaviest thing in the pack; she saw him plainly when he came in from the road, the rope was a big package on top of everything. He desired the whole wide world to witness that this was not a fact. He had carried the rope in one hand and the basket in the other, and what was the use of her having eyes if that was the best they could do for her?

Well, anyhow, she could see one thing plain: no eggs for breaklast. They'd have to scramble them now, for supper. It was too damned bad. She had planned to have steak for supper. No ice, meat wouldn't keep. He wanted to know why she couldn't finish breaking

40 the eggs in a bowl and set them in a cool place.

Cool place! If he could find one for her, she'd be glad to set them there. Well, then, it seemed to him they might very well cook the meat at the same time they cooked the eggs and then warm up the meat for tomorrow. The idea simply choked her. Warmed-over meat, when they might as well have had it fresh. Second-best and scraps and makeshifts,

\section{GLOSSARY}

27 they're all running: the shells are broken and the insides are leaking out.

\section{INFORMAL SPEECH}

24 it would come in: short for "it might come in handy."

28 siliy: foolish.

29 simply: only, merely (otten spoken in defense of oneself).

34 desired the whole wide world to witness (cliché): an exaggerated eftort to emphasize his innocence (He would probably answer: "I'll tell the world it wasn't!")

35 what was the use of ... a dis. paraging put-down expression that she was hall-blind or was 100 stupid to see something obvious.

38 too damned bad: the swear-word adds emphasis to show her annoyance.

39 wouldn't keep: would not stay fresh, would spoil.

43 warm up: reheat.

43 warmed-over: reheated

44 makeshifts: temporary substitutes.

\section{STANDARD VOCABULARY}

26 -disappointed: a little sad because of failed expectations. 28 squeezed: held tightly together. 43 choked: (iit) strangled or killed by blocking the throat. 44 scraps: bits and pieces, good for nothing 
even to the meat! He rubbed her shoulder a little' It doesn't really matter so much, does it, darling? Sometimes when they areve playful, he would rub her shoulder and she anould arch and purr. This time she hissid and almost claued. Ho uns getting reaty to sing that they could surely mannge somchow' when she turned on him and said, if he told her they could manage somehow she would certainly slap his face.

\section{IV}

50 He suallowed the words red hot, his face hurned. He picked up the rope and started to pul it on the top shilf. She would not have it on the top shelf, the jars and tins belonged there; positively she would not have the top shelf cluttered up with a lot of rope. She had borne all the clutter she meant to bear in the flat in tow'n, there was space here at least and she meant to keep things in order.

Well, in that case, he wanted to know what the hammer and nails were doing up there? And why had she put them there when she knew very well he needed that hammer and those nails upstairs to fix the window sashes? She simply slowed down everything and made double work on the place with her insane habit of changing things around and hiding them.

60 She was sure she begged his pardon and if she had had any reason to believe he was going to fix the sashes this summer she would have left the hammer and nails right where he put them: in the middle of the bedroom floor where they could step on them in the dark. And now if he didn't clear the whole mess out of there she would throw them down the well.

Oh, all right, all right-could he put them in the closet? Naturally not, there were brooms and mops and dustpans in the closet, and why couldn't he find a place for his rope

\section{GLOSSARY}

46 arch and purr: behave like a cat when it's happy.

47 hissed ... clawed: behaved like an angry cat.

50 swallowed the words red hot: stopped short, without speaking The analogy suggests suddenly having to swallow very hol food.

51 jars and tins: canned goods and other preserved food.

53 flat: an apartment

55 in that case: then, accordingly

57 window sashes: wooden frames that hold the glass at the bottom of windows.

60 She was sure she begged his pardon: exaggerated formality. de liberately meant to sound sarcastic. 64 well: a deep hole dug in the ground used as a source for drinking water in the country.
INFORMAL SPEECH

47 surely manage somehow (cliche): certainly find a way to cope with their problems (usually said when one has no solutions to propose but is trying to sound hopeful). 48 lurned on him: angrily faced him and spoke sharply.

52 cluttered up: filled with in a mes sy, disorderly way

55 what ... were doing: why they were there (usually implies some. thing should not be there.)

57 simply: Note that, when he used this earlier (ine 29. p. 186), he was defending his own action. What is he doing here?

63 the whole mess: all that worth. less junk.

\section{STANDARD VOCABULARY}

51 belonged: were properly situated or placed, were meant to be. 52 positively: emphatically. 52 had borne: (past participle of to bear) had endured, put up with. 58 insane: mentally deranged. crazy 
outside her kitchen? Had he stopped to consider there were seven rooms in the house and only one kitchen?

He wanted to know what of it? And did she realize she was making a complete fool of 70 herself? And what did she take him for, a three-year-old idiot? The whole trouble with her was she needed something weaker than she was to heckle and tyrannize over. He wished now they had a couple of children she could take it out on. Maybe he'd get some rest.

Her face changed at this, she reminded him he had forgot the coffee and had bought a worthless piece of rope. And when she thought of all the things they actually needed to make the place even decently fit to live in, well, she would cry, that was all. She looked so forlorn, so lost and despairing he couldn't believe it was only a piece of rope that was causing all the racket. What was the matter?

Oh, would he please hush and go away, and stay away, if he could, for five minutes. By all means, yes, he would. He'd stay away indefinitely if she wished. Lord, yes, there

80 was nothing he'd like better than to clear out and never come back. She couldn't for the life of her see what was holding him, then. It was a swell time. Here she was, stuck, miles from a railroad, with a half-empty house on her hands, and not a penny in her pocket, and everything on earth to do; it seemed the moment for him to get out from under. She was surprised he hadn't stayed in town as it was until she had come out and done the work and got things straightened out. It was his usual trick.

\section{GLOSSARY}

70 idlot: a silly fool (lit, a teeble-minded person).

75 decently it to live in (indel): She is hinting that their home needs to be made much more convenient and attractive.

79 by all means: a rather archaic, formal way of saying "Cenainily," "Of course."

82 not a penny in her pocket (cliche): with no money.

83 everything on earth to do (exag): all the housework to do. 64 is it was (cliche): in any case. after all.

85 his usual trick: implying that he would iry any kind of scheme to avoid helping with the work.

\section{INFORMAL SPEECH}

69 what of th?: (the of is stressed) What does that matter?

70 What did she take him for? (stress on take): What did she think he was?

72 take hout on: express negative behavior toward someone who cannot retaliate, or do the same in return. 77 racket: confused noise, din.

78 please hush: please be quiet. 79 Lord: mild swearing.

80 clear out: leave tor good. laking all one's possessions.

80 couldn't for the life of her (cliche): an exaggeration to sound sarcastic

81 what was holding him: what was keeping him at home (sarc).

81 swell (si): fine, wondertul, "great" (sarc).

81 stuck: unable to move.

83 to get out from under: to escape

(all the work that had to be done).

85 got things straightened out: (cliché): put everything in good order.

\section{STANDARD VOCABULARY}

71 heckle: harass or annoy with questions and demands; badger.

71 tyrannize over: rule oppressively, as a dictator would. 76 "forlorn: deserted, wretched, miserable.

76 "despairing: completely hopeless.

79 indefinitely: for an unspecified length of time, perhaps forever. 
It appeared to him that this was going a little far. Just a touch out of bounds, if she didn't mind his saying so. Why had he stayed in town the summer before? To do a halfdozen extra jobs to get the money he had sent her. That was it. She knew perfectly well they couldn't have done it otherwise. She had agreed with him at the time. And that was 90 the only time, so help him, he had ever left her to do anything by herself.

Oh, he could tell that to his great-grandmother. She had her notion of what had kept him in town. Considerably more than a notion, if he wanted to know. So, she was going to bring all that up again, was she? Well, she could just think what she pleased. He was tired of explaining. It may have looked funny but he had simply got hooked in, and what could he do? It was impossible to believe that she was going to take it seriously. Yes, yes, she knew how it was with a man: if he was left by himself a minute, some woman was certain to kidnap him. And naturally he couldn't hurt her feelings by refusing!

Well, what was she raving about? Did she forget she had told him those two weeks alone in the country were the happiest she had known for four years? And how long had 100 they been married when she said that? All right, shut up! If she thought that hadn't stuck in his craw.

She hadn't meant she was happy because she was away from him. She meant she was happy getting the devilish house nice and ready for him. That was what she meant, and now look! Bringing up something she had said a year ago simply to justify himself for

\section{GLOSSARY}

91 he could tell that to. . . . (cliche) really means that she did not believe him.

93 just think what she pleased: a defiant way of saying that he didn't care what she thought

94 simply got hooked in: (iit) was caught like a tish, or was quite help. less and unable to get away. 100 stuck in hls crow (cliche): made him angry so that he had not forgotten it.

\section{INFORMAL SPEECH}

86 going a little far: (indef): meaning that he thought she was exaggerat. ing and he resented what she said. 86 if she didn't mind his saying so (cliche): an exaggerated effort to sound polite.

88 perfectly well: very well indeed. 90 so help him: a short form of the solemn vow or oath, "So help me God." Meant to sound sincere.

93 bring ... up again: stan once more to blame him for something long past.

94 looked funny: seemed odd or strange.

95 take it seriously: consider it really important.

97 hurt her feelings: offend her deeply

98 raving about: talking wildly or angrily, like a mad person.

100 shut up:rude slang for "Be quiet!"

103 devilish (sw): to emphasize anger ano frustration.

\section{STANDARD VOCABULARY}

91 notion: idea, opinion 92 "considerably: in large degree 104 "justify: show onesel" to be free of any blame. 
forgetting her coffee and breaking the eggs and buying a wretched piece of rope they couldn't afford.

\section{VII}

She really thought it was time to drop the subject, and now she wanted only two things in the world. She wanted him to get that rope from underfoot, and go back to the village and get her coffee, and if he could remember it, he might bring a metal mitt for the

110 skillets, and two more curtain rods, and if there were any rubber gloves in the village, her hands were simply raw', and a bottle of milk of magnesia from the drugstore.

He looked out at the dark blue afternoon sweltering on the slopes, and mopped his forehead and sighed heavily and said, if only she could wait a minute for anything, he was going back. He had said so, hadn't he, the very instant they found he had overlooked it?

Oh, yes, well . . rur along. She was going to wash windows. The country was so beautiful. She doubted they'd have a moment to enjoy it. He meant to go, but he could not until he had said that if she wasn't such a hopeless melancholiac she might see that this was only for a few days. Couldn't she remember anything pleasant about the other summers. Hadn't they ever had any fun? She hadn't time to talk about it, and now would he 120 please not leave that rope lying around for her to trip on? He picked it up, somehow it had toppled off the table, and walked out with it under his arm.

Was he going this minute? He certainly was. She thought so. Sometimes it seemed to her he had second sight about the precisely perfect moment to leave her ditched. She had meant to put the mattresses out to sun, if they put them out this minute they would get at least three hours, he must have heard her say that morning she meant to put them out. So of course he would walk off and leave her to do it. She supposed he thought the exercise would do her good.

\section{VIII}

Well, he was merely going to get her coffee. A four-mile walk for two pounds of coffee was ridiculous, but he was perfectly willing to do it. The habit was making a wreck of her,

\section{GLOSSARY}

109 metal mitt for the skillets: a potholder for protection from the hot irying pans.

112 slopes: hillsides

117 hopeless melancholiac: some. one who is incurably depressed 121 toppled oft the table: became unbalanced (top-heavy) and had fallen off.

123 second sight: the ability to "see" the fulure before it happens (clairvoyance).

124 put the mattresses out to sun: carry out all the bedding to get fresh air and sunshine.

\section{INFORMAL SPEECH}

107 drop the subject: talk about something else. 108 from undertoot: from where it was in her way and thus annoying to ner.

111 imply raw: chapped, or chafed and sore

115 run along: usually said to a small child who is being a nuisance or a bother to an adult.

123 ditched (s): deserted. abandoned.

129 making a wreck of her (ciiche) ruining her health.

\section{STANDARD VOCABULARY}

106 couldn't afford: could scarcely manage to pay for.

112 sweltering: steaming with heat $114^{\circ}$ overlooked: failed to notice. 116 "doubted: did not believe. 120 trip on: to catch one's foot and possibily fall.

123 precisely: exactly.

129 "ridiculous: absurd 
130 but if she wanted to wreck herself there was nothing he could do about it. If he thought it was coffee that was making a wrech of her, she congratulated him: he must have an easy conscience.

Conscience or no conscience, he didn't see why the mattresses couldn't very well wait until tomorrow. And, anyhow, were they living in the house, or were they going to let the house ride them to death? She paled at this, her face grew livid about the mouth, she looked quite dangerous, and reminded him that housekeeping was no more her work than it was his: she had other work to do as well, and when did he think she was going to find time to do it at this rate?

Was she going to start on that again? She knew as well as he did that his work brought

$1+0$ in the regular money, hers was only occasional, if they depended on what she made-and she might as well get straight on this question once for all!

That was positively not the point. The question was, when both of them were working on their own time, was there going to be a division of the housework, or wasn't there? She merely wanted to know, she had to make her plans. Why, he thought that was all arranged. It was understood that he was to help. Hadn't he always, in summer?

Hadn't he, though? Oh, just hadn't he? And when, and where, and doing what? Lord, what an uproarious joke.

IX

It was suth a very uproarious joke that her face turned slightly purple, and she screaned with laughter. She laughed so hard she hat to sit doum, and finally a rush of tears spurted from her eyes

150 and poured dow'n into the lifted cormers of her mouth. He dashed toward her and dragged her up to her feet and tried to pour water on her head. The dipper hung by a string on a nail and he broke it loose. Then he tried to pump water with one hand while she struggled in the other. So he gave it up and shook ber instend.

\section{GLOSSARY}

131 she congratulated him (sarc) wished him joy and success. 133 conscience... conscience (indef). never mind talking about conscience

i4) once for all: without ever mentioning it again. (Similar expressions "Enough of that!" and "That s that!") 146 Oh, just hadn't he?: Repetition for its sarcastic effect.

147 uproarious joke: something howlingly funny (tron)

149 rush of tears spurted: a sudden, hysterical switch from laughing to crying

151 dipper: a tin cup with a long handle.
INFORMAL SPEECH

131 easy conscience: a feeling of being free of any guilt or responsibility.

135 ride them to death: harass and annoy them all the time.

137 at this rate: under such difficult conditions as these.

141 get straight: understand the real tacis.

152 gave it up: stopped trying.

\section{STANDARD VOCABULARY}

135 paied: lost color in her face. 135 livid: unnaturally white (usually a sign of great anger)

142 point: the issue being discussed.

152 pump: vigorously move a han. dle (lever) to bring up water from a well. 
She urenched away, crying for him to take his rope and get out, she had simply given him up; and ran. He heard her high-heeled hedroom slippers clattering and stumbling on the stairs.

He went out around the house and into the lane; he suddenly realized he had a blister on his heel and his shirt felt as if it were on fire. Things broke so suddenly you didn't know where you were. She could work herself into a fury about simply nothing. She was terrible, not an ounce of reason. You might as well talk to a sieve as that woman when she got going. 160 Darned if he'd spend his life humoring her! Well, what to do now? He would take back the rope and exchange it for something else. Things accumulated, things were mountainous, you couldn't move them, or sort them out or get rid of them. They just lay and rotted around. He'd take it back. Why should he? He wanted it. What was it anyhow? A piece of rope. Imagine anybody caring more about a piece of rope than about a man's feelings. What earthly right had she to say a word about it? He remembered all the useless, meaningless things she bought for herself: Why? because I wanted it, that's why! He stopped and selected a large stone by the rond. He would put the rope behind it. He would put it in the toolbox when he got back. He'd heard enough about it to last him a lifetime.

\section{$\mathbf{X}$}

When he came back she was leaning against the pust tox beside the road waiting. It was pretty 170 late, the smell of broiled steak floated nose high in the cooling air. Her face was young and smooth and fresh-looking. Her unmanageable fumm black hair was all on end. She waved to him from a distance, and he speeded up. She called out that supper was ready and waiting, was he starved?

You bet he was starved. Here was the coffee. He waved it at her. She looked at his other hand. What was that he had there?

Well, it was the rope again. Hi slopped short. He had meant to exchange it but forgot. She wanted to know why he should exchange it, if it was something he really wanted. Wasn't the air sweet now, and wasn't it fine to be here?

She walked beside him with on hant hooked into his leather belt. She pulled and jostled him a little as he walked, and leaned against him. He put his arm clear around her and patted her stomach.

\section{GLOSSARY}

154 simply given him up (cliche) considered him impossible to understand or communicate with

156 blister: a sore place on the skin trom the shoe's rubbing it.

158 work ... tury: become very an. gry and excited.

159 you might . . . sieve as. . . . talking was utterly useless in this situation.

165 earthly (indef): simply added for emphasis.
INFORMAL SPEECH

157 things broke: circumslances suddenly seemed to change. 158 not an ounce of reason: no intelligent thinking.

159 got going: became very upset.

160 darned H: a euphemism for a swear word.

171 all on end: sticking straight up or out.

172 Wes he starved?: Did he have a good appetile?

173 You bet: a cheerful and emphatic "yes."

175 slopped short: slopped abruptly or suddenly.

\section{STANDARD VOCABULARY}

154 wrenched oway: violenily pulled away.

155 clattering (onomat): making a sharp sound.

155 stumbling: half falling as one walks or runs.

160 "humoring: giving someone whatever he or she wanted. (Note that this usage as a vert has a ditler. eni meaning from the noun, "humor," as we have used it earlier.)

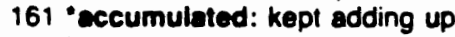
and increasing.

178 jostled (him): bumped against him gently. 
180 They exchanged wary smiles. Coffee, coffee for the Ootsum-Wootums! He felt as if he were bringing her a beautiful present.

He was in love, she firmly believed, and if she had had her coffee in the morning, she wouldn't have behaved so funny. . . There was a whippoorwill still coming back, imagine, clear out of season, sitting in the crab-apple tree calling all by himself. Maybe his girl stood him up. Maybe she did. She hoped to hear him once more, she loved whippoorwills... He knew how she was didn't he?

Sure, he knew how she was.

GLOSSARY

180 the Ootsum-Wootums: a pet name for a small infant. (Lovers often like to use baby talk to each other.) 183 behaved so funny: acted oddly. not like her usual self.

183 whippoorwlll: a night bird whose name comes from its song.
INFORMAL SPEECH

182 firmly believed: was absolutely certain (pretending she had jusi dis. covered the fact)

184 clear out of season: completely ofi-season, or much later than usual. 185 stood him up: left him for anothel !over.

\section{STANDARD VOCABULARY}

180 wary: very cautious or careful 


\title{
1. STUDY QUESTIONS
}

\author{
DISCOVERING THE STORY \\ THROUGH OBSERVATION \\ AND INFERENCE
}

Scene 1

1. Observation: The first paragraph is short, but if you look closely you can obtain a lot of information. What specific details can you find there?

Inference: Based on the information so far, what do you think the man needs at this point, and what is he expecting as he arrives? How are the woman's needs and expectations different from his?

2. Observation: What reason does the woman suggest for his forgetting the coffee? What is her reaction to his bringing home the rope? Is there any connection between the two comments?

Inference: In the third paragraph, between the sentence ending with ". . his eyes" and the one beginning "Why, hadn't . . ." the man probably answers something. What comment from him is implied? What sort of connotation would you associate with her expression, "blot on the landscape"? Can you explain why she feels as she does about it?

Scene 11

3. Observation: In the first paragraph of Scene II, the woman sounds rather accusing, while the man sounds defensive. In the next paragraph, beginning with "Well, thunder. .. ," what changes in tone take place?

Inference: When she makes that long speech, "She thought that was reason enough . . ." do you think she really belietes all she is saying? Why does she say it?

4. Observation: Who gets blamed for the broken eggs? Who does the blaming? Inference: Why do both the woman and the man make such a "big deal" of it?

Scene 111

5. Observation: Do we know, really, how or where he carried the rope on the way home? (Look very closely and be sure.)

Inference: Why is the rope causing so much trouble between them?

6. Observation: Beginning with the second paragraph in Scene III, what complaints is the woman making about their living situation in the country?

Inference: What makes her so angry at the thought of his telling her that "they could manage somehow"?

Scene IV

7. Observation: How do the hammer and nails get into the argument? (Where are they now, and where have they been?)

Inference: Who is talking in the sentence, "She simply slowed ..." and in the sentence, "And now if he ..."? How is the first comment irrclevnnt? How is the second one intemperate? Why do they talk this way?

8. Observation: In what room is the argument taking place? What is it that the man wants to put into the closet?

Inference: Why does the woman talk about "his" rope and "her" kitchen? Do you think she feels satisfied with the role she is assigning to herself? (Give reasons for your opinion.) 
Scene $V$

9. Observation: What are the effects on the woman of those last comments made by her husband?

Inference: Is it true that "only a piece of rope" is causing all the trouble, or are other things also to blame? Why do they both mention the rope so much?

10. Observation: The woman's sudden outburst, beginning with "Oh, would he please hush . . . ." tells us a lot about what is on her mind. Mention four or five grievances that are bothering her.

Inference: Which of these grievances would you call serious, and which do you think are just annoying or inconvenient? What do you think bothers the woman most?

Scene VI

11. Observation: Which of her complaints does her husband try to answer? Exactly what is he responding to in the sentence that begins, "Why had he..."?

Inference: Does his answer satisfy her? Can you figure out from that paragraph beginning, "Oh, he could tell that . . . " what had probably happened last summer?

12. Observation: The two make their strongest charges against each other in the last part of Scene Vl, beginning with the woman's, "Yes, yes, she knew how it was. . ." What is she accusing him of, and how does he answer her?

Inference: Why do you think she interrupts him with "All right, shut up"?

Scene VII

13. Observation: This is the only scene that begins in the middle of someone's speech. What change in the woman's line of argument is taking place at this point? Would you say that her attitude is hardening or softening toward him?

Inference: Even rather innocent-looking objects can take on emotional meaning when a couple is having an argument. What is she implying by asking him to bring the metal mitt and the curtain rods? How about the rubber gloves and the milk of magnesia?

14. Observation: What is the weather like, and how does it affect the two of them differently?

Inference: How do you think the man's wife is trying to make him feel in those two paragraphs beginning with "Oh, yes, well..."? Is she succeeding? 
Scene VIII

15. Observation: What sort of attitude is the man showing toward his wife when he brings up her coffee-drinking? Can you find more examples in Scene VIII of his taking this position toward her?

Inference: Only a short while before, he asked her sadly if they hadn't "ever had any fun." What has been happening to make him change from the way he was talking then?

16. Observation: How do they divide up the housework between them? What contrasts do you see in their viewpoints toward housework? Do you think this is representative of most couples' feelings?

Inference: What do you think the woman might really be trying to say to him? Why is she dissatisfied with his reponse?

Scene $1 X$

17. Observation: The beginning of this scene contains the most action of the whole story. In your own words, explain what is happening here.

Inference: Why is the man acting so frantic (wildly excited)?

18. Observation and Inference: The long paragraph in Scene IX is presented as an interior monologue-as if a person were talking to himself or thinking aloud. Here the man is talking to himself as he starts off to the store.

From the list of words below, choose those that seem to express the man's state of mind as he says (or thinks) each of the following statements. More than one of the words can be applied to some of the statements. Be ready to explain your choices. (Look up the words you don't know). Some of the words may not be needed.

$\begin{array}{llll}\text { accusation } & \text { boredom } & \text { exasperation } & \text { grief } \\ \text { amusement } & \text { contentment } & \text { fault-finding } & \text { hostility } \\ \text { anger } & \text { determination } & \text { forgiveness } & \text { obstinacy } \\ \text { bewilderment } & \text { discouragement } & \text { frustration } & \text { self-righteousness }\end{array}$

"Things broke so suddenly you didn't know where you were."

"She was terrible, not an ounce of reason."

"Well, what to do now?"

"Things accumulated, things were mountainous. . ."

"Imagine anyone caring more about a piece of rope than about

a man's feelings."

"Why? Because I wanted it, that's why!"

Scene $X$

19. Observation: Compare the man's second homecoming with the one in the first paragraph of the story. Which details are similar, and which ones different?

Inference: What inferences might we draw from the odd little passage: "He put his arm around her ... for the Ootsum-Wootums"?

20. Observation: Where and how in this scene does she try to "apologize" for her behavior earlier? Does he accept her apology? How do you know?

Inference: Do you think that this young couple love each other? What might be some of the reasons behind their quarrel? 


\section{EXAM: PART I \\ "ROPE" by Katherine Anne Porter}

TRUE OR FALSE: Circle " $T$ " if the answer is true or " $F$ " if the answer is false.

1. T F The husband came home carrying only a 24 yard coil of rope.

2. T F When the husband discovered he had forgotten his wife's coffee, he said he would return to the village immediately.

3. $T$ F The husband suggested using the rope for a clothesline.

4. T F The husband said she should put the eggs in the refrigerator to keep them cool.

5. T F The Husband said she should have left his hammer and nails in the basement.

6. $T$ F The wife said his rope must not be placed anywhere in her kitchen.

7. $T$ T The husband said her coffee habit was making a wreck out of him.

8. $T$ T The husband tried to calm his wife; he dumped water on her head.

9. $T$ F The wife was waiting by the mailbox when he returned from the village.

10. T F The husband had tried to exchange the rope, but it was too late by the time he got there.

MULTIPLE CHOICE: Circle the correct answer.

11. Who does the husband blame for the broken eggs?
a. cashier
b. grocer
c. bag boy
d. himself

12. Where does husband try to put the rope?
a. near his tool box
b. on the top shelf
c. in the basement
d. on a window sash

13. Which of the following does the wife not ask the him to go back to the village to buy for her?
a. coffee
b. milk of magnesia
c. rubber gloves
d. window cleaner

14. When the husband left to return to the village where does he consider hiding his rope?
a. beside the mailbox
b. under a large stone
c. beneath the porch
d. beside the road

15. What was cooking on the stove when the husband returned from the village?
a. scrambled eggs
b. eggs and potatoes
c. steak and potatoes
d. steak 


\section{EXAM: Part II \\ "Rope" by Katherine Anne Porter}

SHORT ANSWER: Read the quotes from the story. Then answer the questions and state your reasons. Write your answers on a separate sheet of paper.

\section{PART I:}

\section{Scene IV}

He picked up the rope and started to put it on the top shelf, the jars and tins belonged there; positively she would not have the top shelf cluttered up with a lot of rope. She had borne all the clutter she meant to bear in the flat in town, there was space here at least and she meant to keep things in order.

Well, in that case, he wanted to know what the hammer and nails were doing up there? And why had she put them there when she knew very well he needed that hammer and those nails upstairs to fix the window sashes? She simply slowed down everything and made double work on the place with her insane habit of changing things around and hiding them.

She was sure she begged his pardon and if she had had any reason to believe he was going to fix the sashes this summer she would have left the hammer and nails right where he put them: in the middle of the bedroom floor where they could step on them in the dark. And now if he didn't clear the whole mess out of there she would throw them down the well.

Oh, all right, all right--could he put them in the closet?

(1) What kind of housekeeping is important to the wife? Why?

(2) How does her way of keeping house affect the husband?

(3) What is the husband's way of taking care of things?

(4) Explain the personalities of the husband and wife. How are they different?

\section{PART II:}

\section{SCENE $X$}

She walked beside him with one hand hooked into his leather belt. She pulled and jostled him a little as he walked, and leaned against him. He put his arm clear around her and patted her stomach. They exchanged wary smiles. Coffee, coffee for the Ootsum-Wootums? He felt as if he were bringing her a beautiful present.

He was in love, she firmly believed, and if she had had her coffee in the morning, she wouldn't have behaved so funny .... He knew how she was didn't he?

Sure, he knew how she was.

(1) Why does the coffee seem as if it were a beautiful present?

(2) Why does the wife tell the husband that he was in love with her?

(3) How does the wife apologize?

(4) Did the husband accept the apology? How do you know? 
APPENDIX C

NARRATIVE OUTLINE 
THE ROPE

\section{SCENE I}

Time: Late afternoon; summer

Place: A country home; two miles from village

Characters: A young, married couple

Event: Husband Comes Home

Husband and wife exchange greetings

Husband has forgotten to buy coffee for wife

Husband has purchased a 24 yard length of rope

\section{SCENE II}

Event: Couple Discuss Purchase of Rope

Husband defends his purchase

They discover that the eggs have been broken

Wife blames husband; husband blames grocer

\section{SCENE III}

Event: Couple Discuss Dinner

Wife must change dinner plans

Husband suggests: store eggs in a cool place

Wife complains: there is no cool place

Husband tries to calm wife by rubbing her shoulder

Wife threatens to slap husband's face

\section{SCENE IV}

Place: Kitchen

Event: Argument: Where To Put Rope?

Husband tries to put rope on the top shelf in kitchen

Wife says the rope must not be stored in her kitchen

\section{SCENE V}

Event: Accusations

Husband: wife needs someone to heckle and tyrannize

Wife: husband is up to his usual trick

\section{SCENE VI}

Event: Argument: The Other Woman and Last Summer

Wife says husband stayed in town last summer to spend time with another woman 
Husband says he simply got hooked by her

Husband says wife enjoyed her time alone last summer too much

Wife says she only enjoyed getting the house ready for him

\section{SCENE VII}

Event: Standoff

Wife says to drop the subject; she requests supplies from village Husband responds: he is leaving now

Wife says he is leaving now because he does not want to help with the mattresses

\section{SCENE VIII}

Events: Argument: Wife's Coffee Habit and Division of Labor

Husband says she is a wreck because of her coffee habit

Wife says he is easing his conscience

Husband says she is letting house ride them to death

Wife says housekeeping is no more her work than his

Husband says his work makes the regular money

Wife says a division of housework must be planned now

Husband says they already have a plan; he helps in summer

Wife says,"when, where, and doing what?"

\section{SCENE IX}

Place: Kitchen (by the water pump)

Event: The Argument Ends

Wife screams and starts to cry

Husband tries to pour water on wife's head; shakes wife

Wife runs upstairs

Husband leaves house with rope; returns to village

\section{SCENE X}

Time: Late evening

Place: Outside the house, by the mail box

Event: Husband Comes Home

Wife waits for husband; supper is ready

Husband has rope; explains he forgot to exhange it

Wife says if he really wants the rope, why should he exchange it?

Husband gives wife coffee, calls her "Ootsum-Wootsums"

Wife "apologizes" for her behavior

Husband accepts apology 


\section{APPENDIX D}

IRWIN AND MITCHELL "JUDGING RICHNESS OF RETELLINGS" COMPREHENSION EVALUATION MODEL

COMPREHENSION MEASURE 


\section{JUDGING RICHNESS OF RETELLINGS}

The system below was designed by Irwin and Mitchell (1986) to evaluate retellings and compositions. In this system the retellings or written responses are evaluated according to the ideas and facts as the students are able to recall and/or form them. Each student is then assigned a level of use according to these criteria.

LEVEL CRITERIA FOR ESTABLISHING LEVEL

5 Student generalizes beyond text; includes thesis (summarizing statement), all major points, and appropriate supporting details; includes relevant supplementations; show high degree of coherence, completeness, comprehensibility.

4 Student includes thesis (summarizing statement), all major points, and appropriate supporting details; includes relevant supplementations; shows high degree of coherence, completeness, comprehensibility.

3 Student relates major ideas; includes appropriate supporting details and relevant supplementations; shows adequate coherence, completeness, comprehensibility.

2 Student relates a few major ideas and some supporting details; includes irrelevant supplementations; shows some degree of coherence; some completeness; the whole is somewhat comprehensible.

1 Student relates details only; irrelevant supplementations or none; low degree of coherence; incomplete; incomprehensible

$5=$ highest level, 1 = lowest level 


\section{COMPREHENSION MEASURE}

The system below was adapted from the Irwin and Mitchell "Judging Richness of Retellings" (1986) assessment of comprehension model. In this system the sujects are given credit for inferences which are relevant to content. Such inferences are categorized as either supplementations and elaborations. Relevant supplementations are direct assumptions based upon common logic and information provided by the text. In addition, they are intended by the writer. Relevant elaborations are assumptions that go beyond the information provided by the text, and, as such, may not be intended by the author. As such, they may express a cultural norm, personal opinion, or insight. An elaboration may also express a bias on the subject's understanding, but they do not directly contradict the text. The subject's written responses are evaluated. The inferences are categorized and counted and a level of use is assigned. In this adaptation, irrelevant elaborations and supplementations are erroneous statements. They express a misreading of text and are contradictory to the text content. They are not assigned a negative value, but are counted for evaluation of frequency.

LEVEL CRITERIA FOR ESTABLISHING LEVEL

5 Subject never relates text only as response. Subject uses a high level of relevant elaborations and relevant supplementations; subject provides a high level of appropriate supporting details; subject uses no irrelevant elaborations and supplementations.

4 Subject infrequently relates text only as response. Subject uses some relevant elaborations; subject uses a high level of relevant supplementations; subject provides some appropriate supporting details; subject uses little or no irrelevant elaborations and supplementations.

3 Subject occasionally relates text only as response. Subject uses few relevant elaborations and some relevant supplementations; subject provides few appropriate supporting details; subject uses some irrelevant elaborations and supplementations.

2 Subject frequently relates text only as response. Subject uses little or no relevant elaborations and few relevant supplementations; subject provides little or no appropriate supporting details; subject uses few irrelevant elaborations and supplementations.

1 Subject relates text only for most responses; subject uses little or no relevant elaborations and/or supplementations; subject provides little or no appropriate supporting detail; subject uses little or no irrelevant elaborations and supplementations. 
APPENDIX E

SAMPLE EXAM AND EVALUATION PROCEDURE 
106

Part I

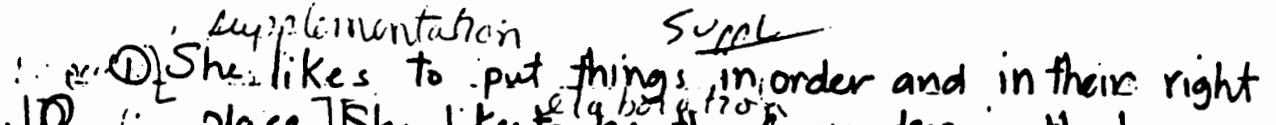

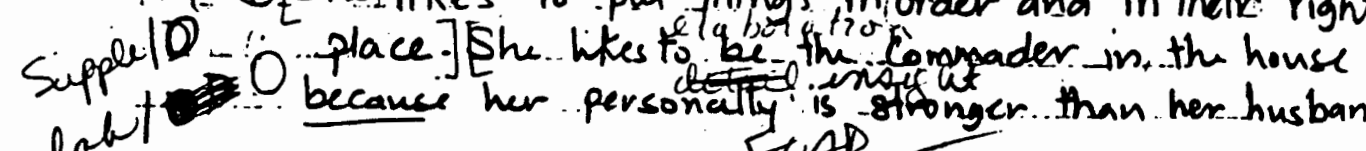
because her personalty is stronger. than here husband] EAR

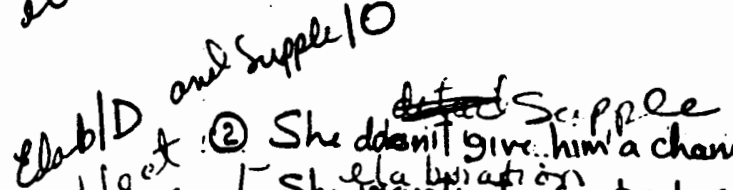

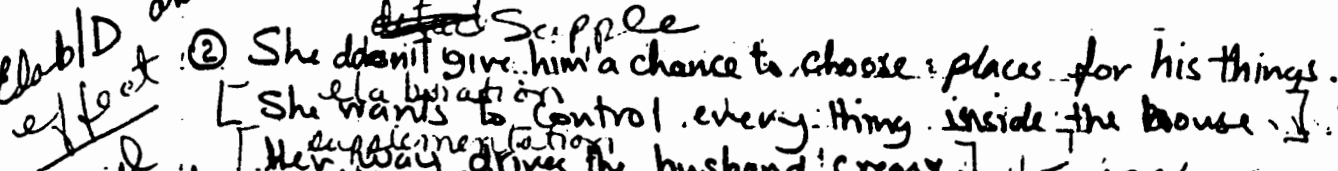

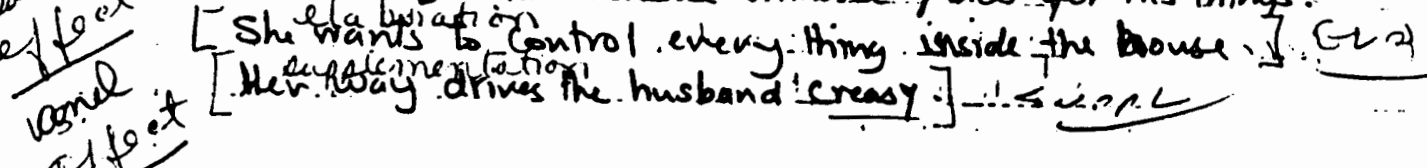
as y

(3) The husband's way of taking Care of things ['I think supp. puffed: he is a careless and he does nit care 7 by keeling his of the red room floor is aged example. deffuil

(4) The wife as I said (1) has a solution strong personalty and She feds that shiletcould Control emery thing inside the house and she tabs that (3) she ahuray right and every

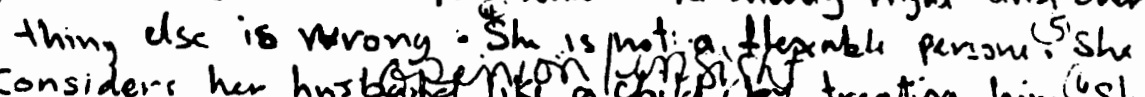

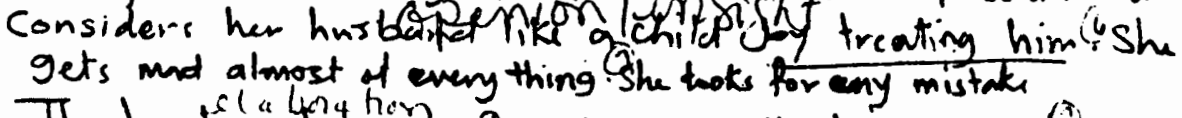

2 elablD

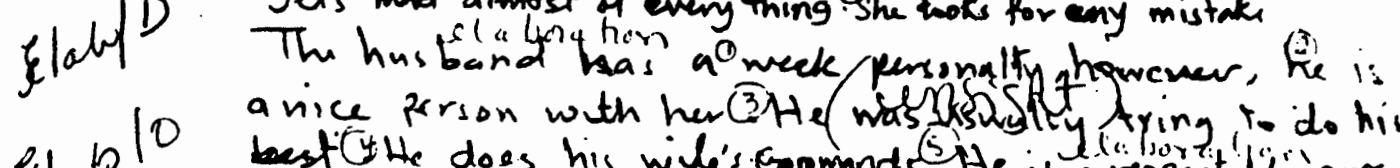

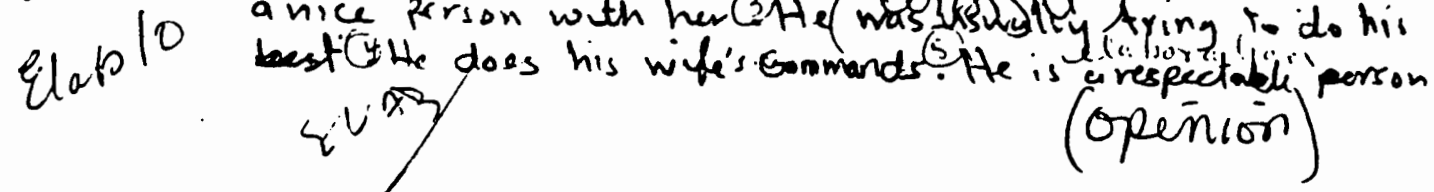
iv i 


\section{Part II}

(1) Because being the caffee brought to her chenged her satintionin and sotve the mistake between them. The

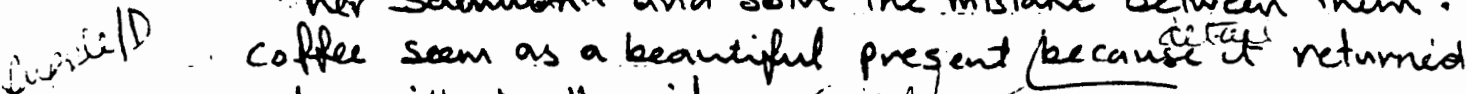
the smille to the wife. Silfif

(2) Because beside what she had done tote', him, he trikel.... accepted her smile and put his arm clear cround her $\operatorname{pip} i \mid D$ and fatted her stomach? If he does nit love her why did he do that? jovify

(3) She apologizied by her attunde, by her behavier - whin ste walked beside him with one hand hooked into his - leather bett and pulled and jostiel shim a litile as he walked and leaved agaist him- Su

(4) Yes he accepted her apology. Because he put his arm dear around her and patted her stomach and exchanged wary smiks with her. 
EVALUATION PROCEDURE

Part I:

QUESTION 1: What kind of housekeeping is important to the wife? Why?

Subject response:

She likes to put things in order and in their right place. She likes to be the commader in the house because her personally is stronger than her husband.

Evaluation:

Supplementation: Subject integrates two ideas from text and summarizes : "positively she would not have the top shelf cluttered up with a lot of rope," and "she meant to keep things in order."

Elaboration: Subject expresses an opinion/insight regarding the wife as

"commader" and that "her personally is stronger than her husband."

QUESTION 2: How does her way of keeping house affect the husband?

Subject response:

She doesn't give him a chance to choose places for his things. She wants to control everything inside the house. Her way drives the husband creazy.

Evaluation:

Supplementations: Subject has integrated and summarized several ideas: (1) "positively she would not have the top shelf cluttered up;" (2) "he wanted to know what the hammer and nails were doing up there;" (3) "why had she put them there when she knew very well he needed that hammer and those nails upstairs;" (4) "if he didn't clear the whole mess out of there she would throw them down the well," and (5) she simply slowed down everything and made double work on the place with her insane habit of changing things."

Elaboration: Subject expresses an opinion beyond immediate context with statement, "she wants to control everything in the house."

QUESTION 3: What is the husband's way of taking care of things?

Subject response:

The husband's way of taking care of things I think he is a careless and he doesn't care by keeping his thing any were leaving the hammer and nails in the middle of the bedroom floor is a good example. 
Evaluation:

Supplementation: The subject supported his inference regarding the "careless" manner of the husband and that "he doesn't care by keeping his thing any were," by paraphrasing text: "leaving the hammer and nails in the middle of the bedroom floor is a good example." (Possible elaboration because response is constructed as an opinion.)

QUESTION 4: Explain the personalities of the husband and wife. How are they different?

Subject response:

The wife as I said has a strong personalty and she feels that she could control every thing inside the house and she feels that she alway right and every thing else is wrong. She is not a flexible person. She considers her husband like a child by treating him. She gets mad almost at every thing. She looks for any mistake. The husband has a weak personalty, however, he is a nice person with her. He was usually tring to do his best. He does his wife's commands. He is a respectable person.

Evaluation:

Elaborations: Subject expresses opinions beyond the text about both the wife and the husband based on what he has determined to be their personalities and basic natures resulting in certain temperaments and behaviors with regard to one another. The wife is "strong" while the husband is "weak." The husband is a "nice person" who is "usually tring to do his best." and "does his wife's commands." In his opinion, the wife is not "flexible," "she gets mad at almost every thing," and "she looks for any mistake." The subject expresses an insight, "she considers her husband like a child." The subject concludes that given all the foregoing, "he is a respectable person."

Part II:

QUESTION 1: Why does the coffee seem as if it were a beautiful present? Subject response:

Because being the coffee brought to her changed her satution and solve the mistake between them. The coffee seem as a beautiful present because it returned the smile to the wife.

Evaluation:

Supplementation: Subject integrates ideas from elsewhere in the text to support the inference that "the coffee brought to her changed her satution and solved the mistake between them." Subject rephrases text "they exchanged wary smiles" to "returned the smile to the wife." 
QUESTION 2: Why does the wife tell the husband that he was in love with her?

Subject response:

Because beside what she had done to him, he accepted her smile and put his arm clear around her and patted her stomach. If he doesn't love her why did he do that?

Evaluation:

Supplementation: With the comment"beside what she had done to him," subject has integrated text from elsewhere. to support his supplemental inference stated as a question: "if he doesn't love her why did he do that?" with the statement "he accepted her smile and put his arm clear around her and patted her stomach" the subject has integrated ideas, paraphrased and summarized.

QUESTION 3: How does the wife apologize?

Subject response:

She apologizied by her attitude, by her behavier when she walked beside him with one hand hooked into his leather belt and pulled and jostled him a little as he walked and leaned agaist him.

Evaluation:

Supplementation: Subject infers that it was "by her attitude, by her behavier" and then supports the inference by integrating ideas from two sentences into one statement.

QUESTION 4: Did the husband accept the apology? How do you know?

Subject response:

Yes, he accepted her apology. Because he put his arm clear around her and patted her stomach and exchanged wary smiles with her.

Evaluation:

Supplementation: The question makes a supplemental inference that the wife has apologized even though no actual statement of apology was made by the wife. The subject supported this inference by stating,"yes, he accepted her apology." The subject further supports the inference by integrating ideas from two sentences into one statement 
APPENDIX $F$

RECONSTRUCTION OF SEMANTIC MAP 


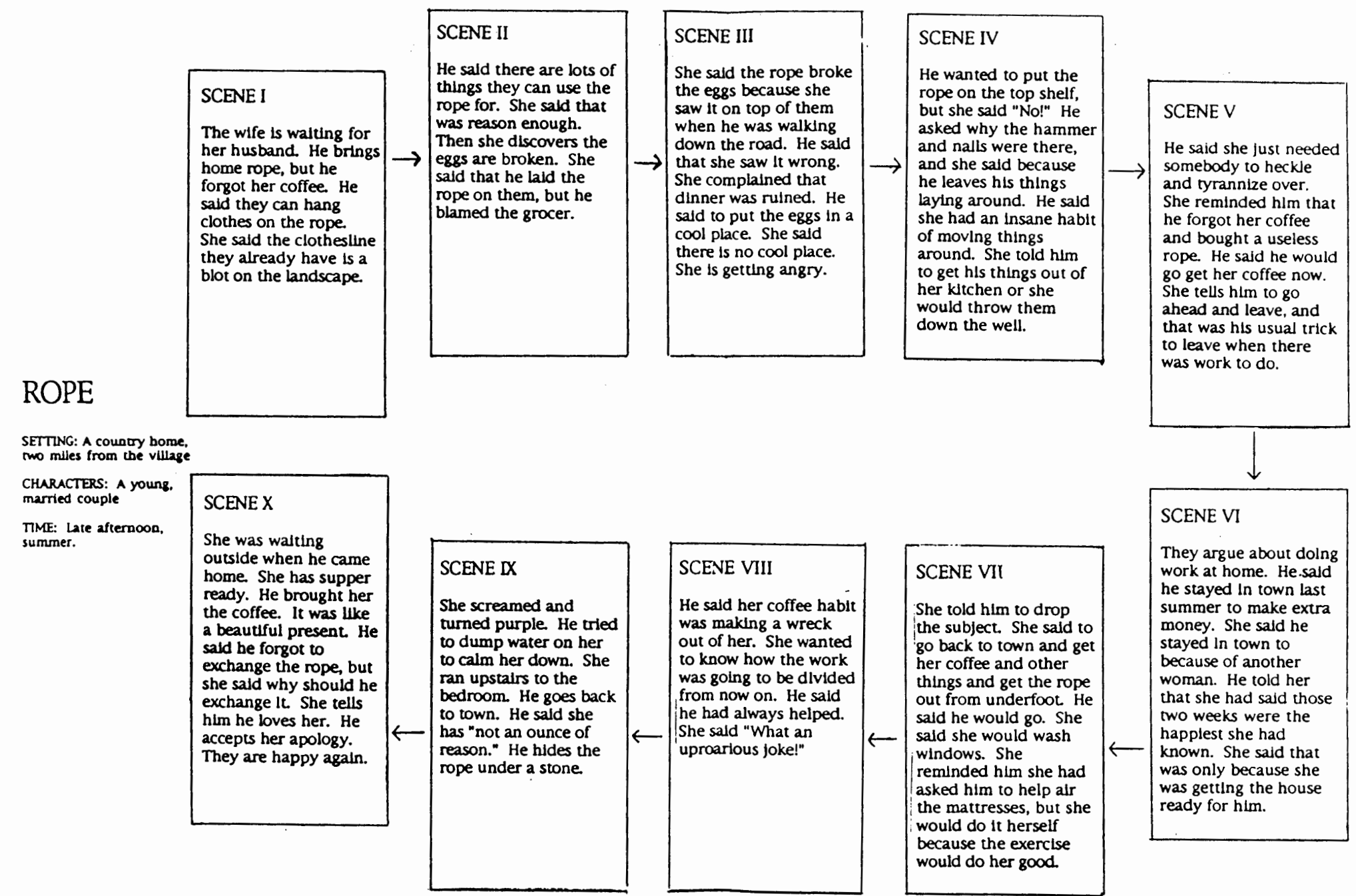

